\title{
Surface Roughness Prediction and Minimization in 5-Axis Milling Operations of Gas Turbine Blades
}

\section{Arameh Eyvazian ( $\triangle$ ARAMEH.EYVAZIAN@GMAIL.COM )}

Qatar University

Farayi Musharavati

Qatar University

Afrasyab Khan

Qatar University

Mohsen Soori

Qatar University

Tamer A. Sebaey

Qatar University

Saleh Mobayen

Qatar University

Naeim Farouk

Qatar University

\section{Research Article}

Keywords: Turbine blades, Surface roughness, 5-Axis CNC machine tools, Virtual machining

Posted Date: February 12th, 2021

DOl: https://doi.org/10.21203/rs.3.rs-219101/v1

License: (c) (1) This work is licensed under a Creative Commons Attribution 4.0 International License.

Read Full License 


\title{
Surface Roughness Prediction and Minimization in 5-Axis Milling Operations of Gas Turbine Blades
}

\author{
Arameh Eyvazian ${ }^{* 1}$, Farayi Musharavati ${ }^{1}$, Afrasyab Khan ${ }^{2}$, Mohsen Soori ${ }^{3}$, Tamer A. Sebaey ${ }^{4,5}$ Saleh \\ Mobayen $^{6}$ and Naeim Farouk ${ }^{7}$
}

${ }^{1}$ Department of Mechanical and Industrial Engineering, College of Engineering, Qatar University, P.O. Box 2713, Doha, Qatar

${ }^{2}$ Institute of Engineering and Technology, Department of Hydraulics and Hydraulic and Pneumatic Systems, South Ural State University, Lenin Prospect 76, Chelyabinsk, 454080, Russian Federation.

${ }^{3}$ Department of Mechanical Engineering, Eastern Mediterranean University, Famagusta, North Cyprus, Mersin 10, Turkey

${ }^{4}$ Engineering Management Department, College of Engineering, Prince Sultan University, Riyadh, Saudi Arabia

${ }^{5}$ Mechanical Design and Production Department, Faculty of Engineering, Zagazig University, P.O. Box 44519, Zagazig, Sharkia, Egypt

${ }^{6}$ Future Technology Research Center, National Yunlin University of Science and Technology, 123 University Road, Section 3, Douliou, Yunlin 64002, Taiwan, R.O.C.

${ }^{7}$ Mechanical Engineering Department, College of Engineering, Prince Sattam bin Abdulaziz University, Alkharj 16273, Saudi Arabia

*Corresponding Author, E-Mails: eyvazian@qu.edu.qa (Arameh Eyvazian),

E-Mails: farayi@qu.edu.qa (Farayi Musharavati), khana@susu.ru (Afrasyab Khan)

Mohsen.soori@gmail.com, Mohsen.soori@emu.edu.tr (Mohsen Soori), sepaey@hotmail.com (Tamer A. Sebaey), mobayens@yuntech.edu.tw (Saleh Mobayen), naeem1950@hotmail.com (Naeim Farouk)

\begin{abstract}
:
To enhance the quality of machined parts, virtual machining systems are presented in this study. In the turbine blades, the minimization of the surface roughness of the blades can decrease the Reynolds number to decrease the loss of energy in power generation. Due to difficulties of polishing process in minimizing the surface roughness of machined blades, the optimized machining parameters for minimizing the surface roughness is an effective solution for the problem. In this study, a virtual machining system is developed to predict and minimize the surface roughness in 5-Axis machining operations of gas turbine blades. To minimize the surface roughness, the machining parameters were optimized by the Genetic algorithm. To validate the developed system, the turbine blades were machined using a 5-Axis CNC machine tool and the machined blades were measured using the CMM machine to obtain the surface roughness of machined parts. So, a $41.29 \%$ reduction in the measured surface roughness and a $42.09 \%$ reduction in the predicted surface roughness are obtained using the optimized machining parameters. The developed virtual machining system can be applied in the machining process of turbine blades to enhance the surface quality of machined blades and thus improve the efficiency of gas turbines.
\end{abstract}


Keywords: Turbine blades, Surface roughness, 5-Axis CNC machine tools, Virtual machining

\section{1- Introduction}

The process of machining operations was simulated in virtual environments. The machining parameters of the chip formation process can be optimized to increase the quality of machined parts. One of the most important characters of the machined parts is their surface roughness with a great influence on the fatigue behavior of the workpiece under actual working conditions. In the compressor section of a gas turbine, the surface roughness of machined blades can affect the Reynolds number which can lead to the formation of laminar separation bubbles. The velocity profile in the boundary layer is a plumper on a rough surface than on a smooth surface turbine blade. The aerodynamic loss is lower at low Reynolds numbers, but becomes significantly large at high Reynolds number [1]. As a result, the loss of energy in the gas turbines can be decreased by minimizing the size of surface roughness for the machined blades to increase the efficiency of the power plants. The surface roughness of machined parts is under the influence of cutting conditions such as machining parameters, cutting tool characteristics, and workpiece properties.

To decrease the surface roughness in the machined turbine blades, the polishing process can be applied which can create some problems for accuracy and reliability of machined blades and can increase cost of blades machining operations. The dimensional accuracy of the machined blades are decreased due to the polishing process in the surface roughness minimization. Also, the polishing process can cause deformation in the machined blades which is not acceptable for the accurate parts. Robotic polishing can provide desired accuracy which can increase cost of manufacturing process for turbine blade machining operations. Moreover, the polishing process can increase residual stress in the machined blades which can cause failure for the blades by decreasing the fatigue life [2]. As a result, the optimizer machining parameters which can minimize the surface roughness can provide an effective solution for increasing accuracy and reliability of machined turbine blades in the power plants.

The optimization method can be applied to the machining parameters to minimize the surface roughness of the machined parts. The surface quality of machined turbine blades can be increased by optimizing the machining parameters to increase the efficiency of gas turbines. In this context, a virtual machining system can predict and minimize the surface roughness of machined turbine blades and provide an efficient methodology in the process of energy production by increasing the productivity of gas turbine in power plants.

\section{2- Review of Research works analyzing and minimizing the surface roughness in the machining operations}

A review of surface roughness effects in gas turbines was presented by Bons [3] to analyze the role of surface roughness of blades in gas turbines performances. To increase the surface quality of machined turbine blades, Kiran and Clement investigated the surface quality of steel turbine blade in the turning process [4]. The influence of milling and grinding on machined surface roughness and fatigue behavior of GH4169 superalloy workpieces was investigated by Li et al. [5] to enhance the fatigue life of machined parts under actual working conditions. A dynamic surface roughness monitoring system was developed by Khorasani and Yazdi based on artificial neural networks (ANN) in milling operation [6] to analyze the effects of cutting speed, feed rate, and depth of cut on the surface roughness minimization process. An intelligent neural-fuzzy model was presented by Huang [7] for an in-process surface roughness monitoring system at the end of milling operation to develop a surface roughness monitoring system. Optimization of cutting parameters to minimize the surface roughness at the end of milling process was presented by Ribeiro et al. [8] using the Taguchi method to minimize the arithmetic mean surface roughness in the machined parts. Ribeiro et al. [9] optimized the machining parameters to improve the surface quality and analyze the influence of cutting parameters to minimize the surface roughness. To improve the quality and productivity of ball-end milling operation, the influence of machining parameters on the surface roughness and material removal 
rate was studied by Quintana et al. [10]. The cutting tool parameters as well as cutting forces are investigated by Dabade et al. [11] to increase quality of machined composite surfaces. The effects of material anisotropy of ductile materials in cutting forces is studied by Chen et al. [12] in order to increase surfaces roughness of machined parts. To increase the surface roughness in the machined parts using the EDM machines, the effects of cutting forces is analyzed by Tosun et al. [13]. A low frequency underwater metastructure composed by helix metal and viscoelastic damping rubber systems are developed by Gao and Zhang [14]. New Stabilization Results for Semi-Markov Chaotic Systems with Fuzzy Sampled-Data Control is developed by Wu et al. [15]. Differential received signal strength based RFID positioning for construction equipment tracking is in investigated by Wu et al. [16]. Influence of the position of artificial boundary on computation accuracy of conjugated infinite element for a finite length cylindrical shell is presented by Huang et al. [17]. Theoretical modeling and experimental verification of swing vibration control of suspended structures using the active rotary inertia driver system is presented by Zhang et al. [18]. A Rapid and efficient route to automatic metasurface design using the Deep Learning method is presented by Qiu et al. [19]. Dimensional accuracy and surface finish in the dry turning operations is studied by Rafai and Islam [20] to increase quality and accuracy of machined parts. Applications of the hybrid neural network in the surface roughness prediction is studied by Jesuthanam et al. [21] in order to increase surface quality of machined parts.

Tangjitsitcharoen et al. [22] predicted the surface roughness in the ball-end milling process utilizing a dynamic cutting force ratio to increase the surface quality of machined parts. Debnath et al. assessed the influence of cutting fluid conditions and cutting parameters on surface roughness and tool wear in the turning process using Taguchi method [23]. The effect of machine tool's spindle forced vibrations on surface roughness, dimensional accuracy, and tool wear in vertical milling operations of AISI P20 was investigated by Zahoor et al. [24]. The impacts of optimized machining parameters on the surface roughness were evaluated by Karabulut and Karakoç in the milling of Al7075 and open-cell SiC foam composite [25]. Nurhaniza et al. also analyzed the effect of machining parameters on the surface roughness during end milling of CFRP-aluminium composite laminates [26]. Kant and Sangwan also predicted and optimized the machining parameters to minimize the power consumption and surface roughness to decrease the surface roughness of machined parts as well as machining energy consumption during the milling operations [27]. The cutting force and surface roughness were modeled and optimized in the milling process of Inconel 738 by Imani et al. using hybrid ANN and GA [28] to analyze and optimize the effects of milling parameters such as cutting speed, feed rate, the axial depth of cutting, and coolant to the surface roughens of machined super-alloys.

To analyze and modify the machining operations in virtual environments, virtual machining systems were presented by Soori et al. [29-32]. Virtual machining system and application was also presented by Altintas and Merdol [33] to optimize the condition of milling operations.

An advanced virtual machining system was developed in this study to minimize the surface roughness in milling operations of turbine blades. An optimization methodology was also applied based on the genetic algorithm to minimize the surface roughness of machined blades. To validate the presented techniques, real turbine blades were machined by the 5 -axis CNC machine tool. The CMM machine tool was also employed to measure the surface roughness. To present the effectiveness of the developed virtual machining systems in terms of quality improvement in turbine blade machining operations, the reduction of surface roughness in machined turbine blades by optimizing the machining parameters was presented in the diagrams. The accuracy and efficiency of the process of turbine blades machining operations can be increased by applying the developed algorithm.

The rest of this paper is organized as follows: the calculation method of the cutting forces is addressed in section 3. The surface roughness model is presented in section 4 . The optimization procedure to minimize the surface roughness is also described in section 5 . Section 6 addressed the developed virtual machining system to predict and minimize the surface roughness in milling operations. Finally, the developed virtual machining system was validated for prediction of the deflection error and obtaining the optimized machining parameters to minimize the surface roughness of the machined turbine blade in section 7.

\section{3- Cutting forces model}


To calculate the cutting forces in 5-axis machining operations, the cutting force model developed by Zhang et al. [34] was applied. The 5 -axis milling operation of free form surfaces is illustrated in Figure 1 [34].

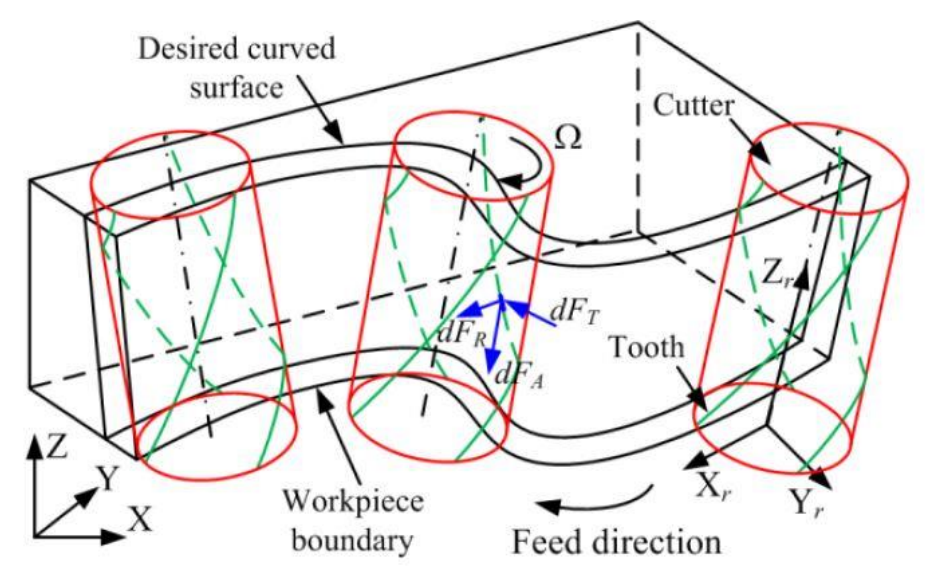

Fig. 1. The 5-axis milling operations of free form surfaces [34].

The XYZ planes are defined to describe the tool motion process, workpiece geometry, and tool path in machining operations. Moreover, $X_{r} Z_{r} Y_{r}$ is created to describe the tool rotation coordinate system in machining operations. The cutting forces in the differential format wasapplied to the $j_{t h}$ axial disk element of the $i_{t h}$ tooth at the rotation angle of $\phi_{i, j}(t)$ :

$$
\left\{\begin{array}{l}
d F_{T, i, j}(t)=\left(k_{t s} h(i, j, t) d b+k_{t p} d b\right) W\left(\theta\left(\phi_{i, j}(t)\right)\right) \\
d F_{R, i, j}(t)=\left(k_{r s} h(i, j, t) d b+k_{r p} d b\right) W\left(\theta\left(\phi_{i, j}(t)\right)\right) \\
d F_{A, i, j}(t)=\left(k_{a s} h(i, j, t) d b+k_{a p} d b\right) W\left(\theta\left(\phi_{i, j}(t)\right)\right)
\end{array}\right.
$$

Where $h(i, j, t)$ is the instantaneous uncut chip thickness of the $j_{t h}$ axial disk element of the $i_{t h}$ tooth at $t$ and $d b$ denotes the axial height of cutting disk element. Moreover, the coefficients of shearing-specific cutting force in different directions as tangential, radial and axial can be shown as $k_{q s}=a_{q s}+b_{q s} e^{c_{q s} h(t)}(q=t, r, a)$. Also, the coefficients of plowing-specific cutting force in different directions as tangential, radial, and axial direction can be presented as, $k_{q p}=a_{q p}+b_{q p} e^{c_{q p} h(t)}(q=t, r, a)$. The instantaneous chip thickness determination in a 5 -axis CNC machining operations was presented by Luo et al. [35] as shown in Figure 2. 

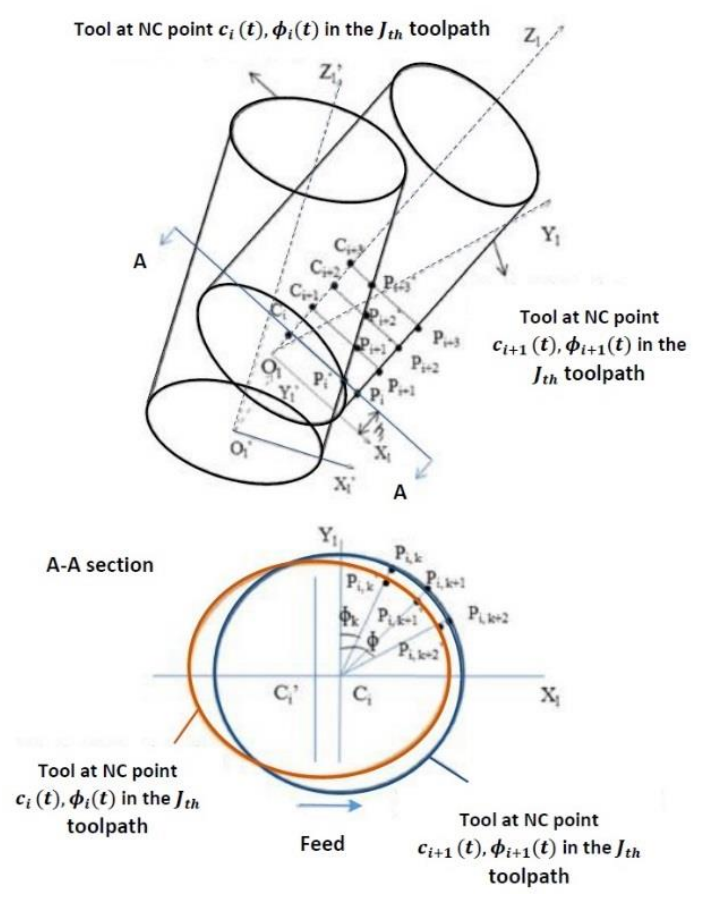

Fig. 2. The chip thickness determination along the machining paths free form surfaces using 5 -axis $C N C$ machine tools [35].

To determine that the condition of disk element is in or out of cutting operation, $W(\theta)$ can be presented as:

$W\left(\theta\left(\phi_{i, j}(t)\right)\right)=\left\{\begin{array}{lr}1 & \theta_{s t, i, j} \leq \theta\left(\phi_{i, j}(t)\right) \leq \theta_{e x, i, j} \\ 0 & \text { Others }\end{array}\right.$

Where $\theta_{e x, i, j}$ stands for entry and exit angles of $j_{t h}$ disk element on the $i_{t h}$ tooth, respectively (see Figure 3) [34].

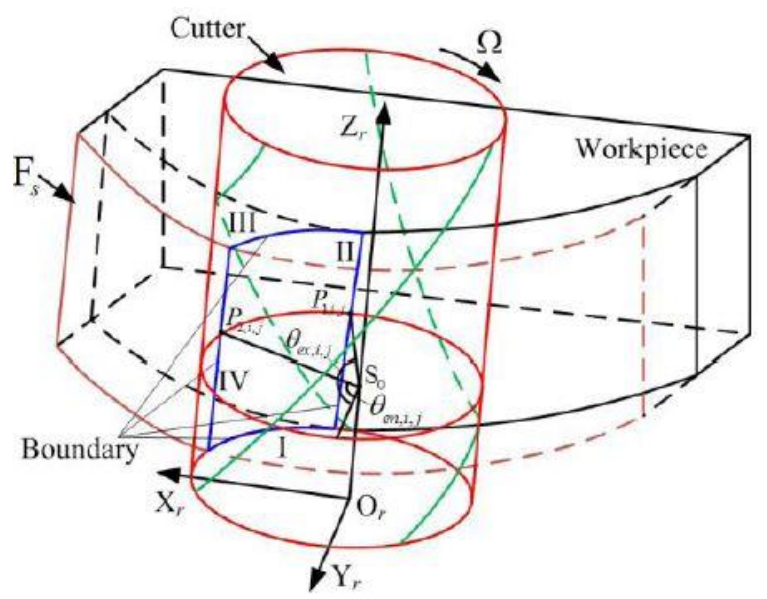

Fig. 3. Entry and exit angle model of the cutting tool [34].

Therefore, the overall cutting forces applied to the t moment can be calculated by summing three cutting forces acting on the disk element within the axial depth of cut as is depicted in Eq. (3). 
$\left[\begin{array}{l}F_{c, x}(t) \\ F_{c, y}(t) \\ F_{c, z}(t)\end{array}\right]=\sum_{i} \sum_{j} \operatorname{Rot}\left[\begin{array}{l}d F_{T, i, j}(t) \\ d F_{R, i, j}(t) \\ d F_{A, i, j}(t)\end{array}\right]$

Where Rot is the cutter rotation matrix. With the aid of the transformation relationship matrix in 5-axis machine tool, the total cutting force components acting on the workpiece can be obtained as:

$\left[\begin{array}{l}F_{w, x}(t) \\ F_{w, y}(t) \\ F_{w, z}(t)\end{array}\right]=-\operatorname{RotC} \cdot \operatorname{Rot} B\left[\begin{array}{l}F_{c, x}(t) \\ F_{c, y}(t) \\ F_{c, z}(t)\end{array}\right]$

\section{4- Surface Roughness model}

The mathematical equation of surface roughness was presented by Reddy and Rao [36]:

$Y=\varphi(S, f, \alpha, r)+\epsilon$

Where $Y$ is the machining response, $\varphi$ denotes the response function and $S, f, \alpha, r$ are milling variables as spindle speed, feed rate, Radial rake angle (degree), and cutting tool nose radius $(\mathrm{mm})$, respectively and $\in$ represents the error normally distributed about the observed response $Y$ with zero mean. The relationship between surface roughness and other independent variables can be represented by:

$R_{a}=C S^{a} f^{b} \alpha^{c} r^{d}$

Where $C$ is a constant and $a, b, c$ and $d$ are exponents.

The surface roughness equation can be obtained using the experimental results as:

$R_{a}=0.6088(S)^{-0.4638}(f)^{0.4461}(\alpha)^{0.1129}(r)^{0.1290}$

Where $S, f, \alpha, r$ are milling variables as spindle speed, feed rate, Radial rake angle (degree), and cutting tool nose radius $(\mathrm{mm})$, respectively.

\section{5- The optimization procedure to minimize the surface roughness}

In order to minimize the surface roughness in the machined parts, the machining parameters were optimized using the genetic algorithm. In the genetic algorithm optimization process, the natural process of evolution and a set of chromosomes are introduced. The initial population for the optimization process was created using the binary encoding process. To provide evaluation criteria in the optimization process and rank the chromosomes in population, the fitness function can be calculated as presented in Eq. (8) [37].

$F(x)=\frac{1}{1+f(x)}$

Where fitness function and objective function are $F(x)$ and $f(x)$, respectively. The main operators of the algorithms are reproduction, crossover, and mutation. The operators are applied to the initial population of the optimization process accelerate the convergence to the optimized parameters.

The cutter deviated from the theoretical positions due to the cutting forces in the chip formation process. As a result, the cutting tool moves away from the desired machining path giving rise to the tool deflection error in the machine parts.

The tool deflection equation used by Rao and Rao [38] and Law et al. [39] can be determined by Eq. (9).

$\delta=\frac{F}{3 E I}(L-0.5 a)^{3}$ 
Where $F$ is cutting forces, $a$ shows the axial depth of cut, $I$ represents the equivalent moments of area. $E$ indicates Young's module of elasticity and $L$ is the tool length that is out of the spindle.

Moreover, the time of machining operation should be minimized to decrease the cost of machined parts. The mathematical equation of machining time is presented in Eq. (10) [40].

$t_{m}=\frac{k}{f}$

Where $k$ is the distance of cutting tool to reach to the operational zone and $f$ represents the feed rate.

Also, cutting tool life should be maximized to decrease the cost of machining operation. The cutting tool life can be defined by Eq. (11) [40].

$T_{L}=\left(\frac{60}{Q}\right)\left[\frac{C\left(\frac{G}{5}\right)}{V(A)^{w}}\right]^{\frac{1}{m}}$

Where $Q$ is the contact proportion of cutting edge with the workpiece per revolution, $C$ is 33.98 for the HSS tools and 100.05 for the carbide tools, $g=0.14, V$ is cutting speed ( $\mathrm{mm} /$ minutes), $w=0.28, m$ is 0.15 for HSS tools while it reached a maximum of 0.30 for carbide tools, $G$ and $A$ are the slenderness ratio and chip cross-section as shown by Eq. (12) and (13) respectively [40].

$G=\frac{a}{f}$

$A=a . f$

Where $a$ shos the depth of cut and $f$ is feed rate in machining operations.

The surface roughness of machined parts can be decreased by reducing the feed rate and increasing the spindle speed according to Eq. (7). However, the machining time will be increased by reducing the feed rate according to Eq. (10). Moreover, increasing the spindle speed can decrease the cutting forces according to Eq. (4). Thus, the tool deflection error should be decreased to increase the accuracy of machined parts according to Eq. (9). Furthermore, the cutting tool life can be declined by raising the spindle speed according to Eq. (11). Therefore, the presented mathematical models of the surface roughness, cutting forces, tool deflection error, time of machining operations, feed rate, and cutting tool life are related together which should be considered in the optimization problem. The objective function of the optimization process is minimization of surface roughness of machined turbine blades by using the optimized machining parameters. As a result, an optimization process of machining parameters (Figure 4) should be implemented to calculate the optimized feed rate and spindle speed during the machining operation. 


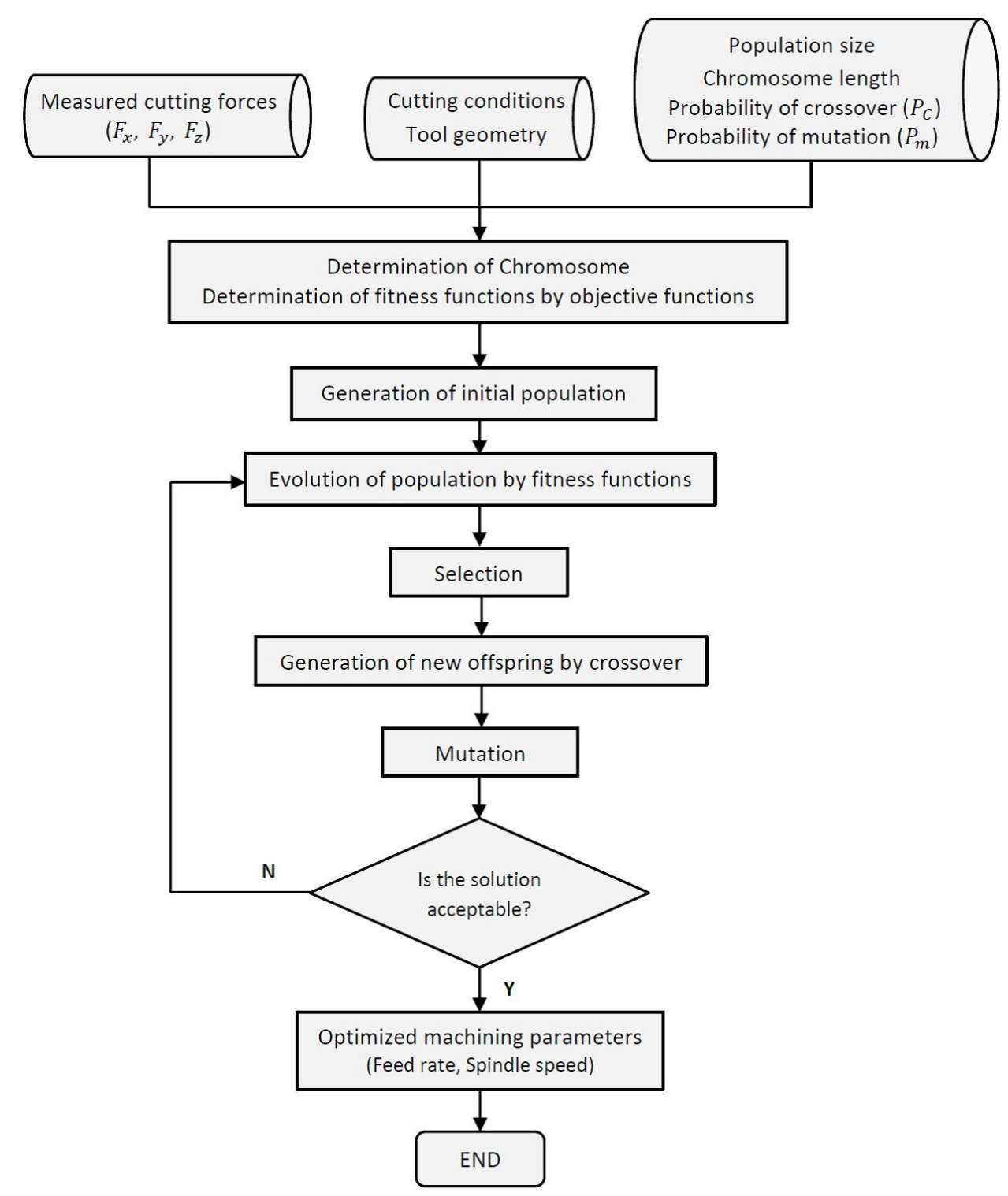

Fig. 4. The optimization process of machining parameters.

The algorithm of the optimization method is presented in appendix A.

Matlab programming language was used to optimize the machining parameters (i.e. minimize the surface roughness). As a result, the optimized feed rate and spindle speed were obtained to minimize the surface roughness of machined parts.

\section{6- Virtual machining system to predict and minimize the surface roughness}

The Visual Basic programming language was used in this study to develop the presented virtual machining system. The nominal machining path, the geometry, and material properties of the cutting tool as well as the CAD model of the workpiece are the inputs of the system. The developed virtual machining system can read the NC codes of machining operations and can calculate the cutting forces regarding the cutting tool details and parameters of machining operations. So, cutting forces at each position of the cutting tool along machining paths can be calculated 
in order to be used in the optimization process of machining parameters. The cutting force calculator dialogue box is shown in Figure 5.

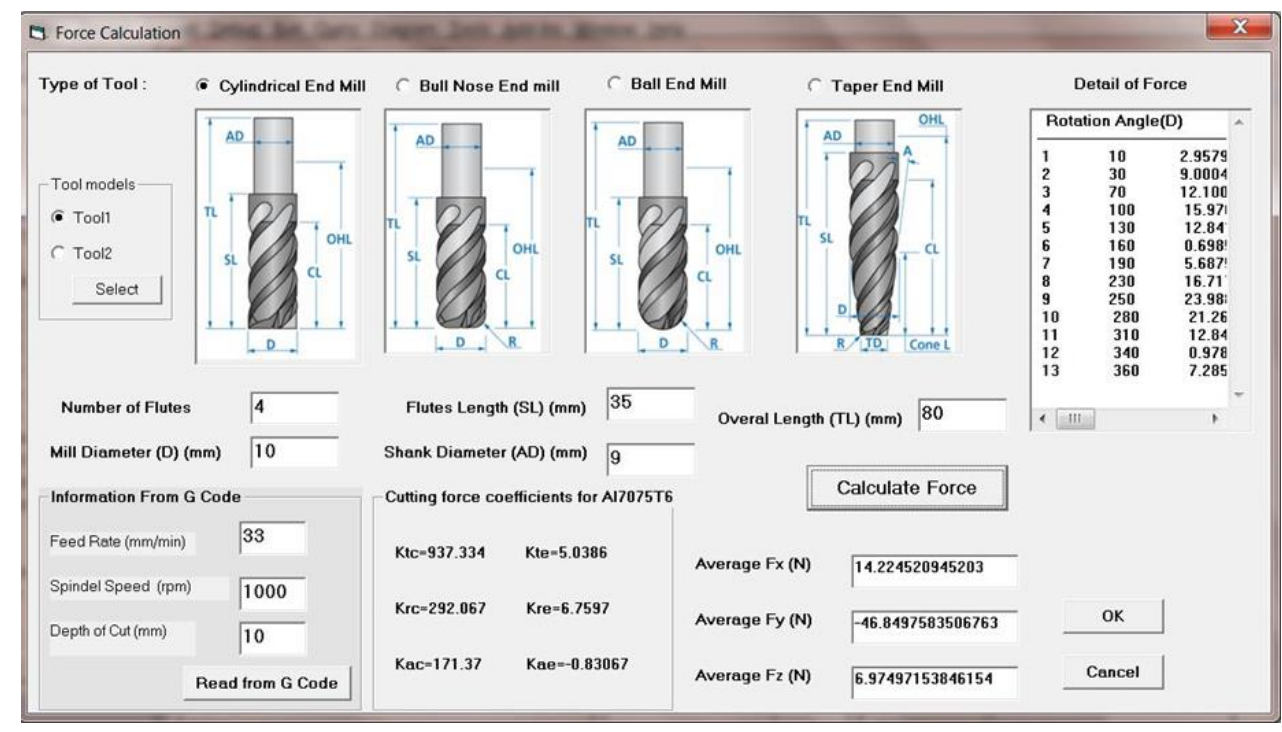

Fig. 5. Dialogue box of cutting force calculator.

The developed virtual machining system can calculate the surface roughness of machined surfaces using the machining parameters according to the cutting conditions. As a result, the size of surface roughness in the machined parts can be predicted using the system in order to be analyzed and minimized. To minimize the surface roughness, the optimization techniques based on the genetic algorithm is applied in the developed virtual machining system. The flowchart and strategy of the virtual machining system in cutting force calculation and surface roughness prediction are shown in Figure 6.

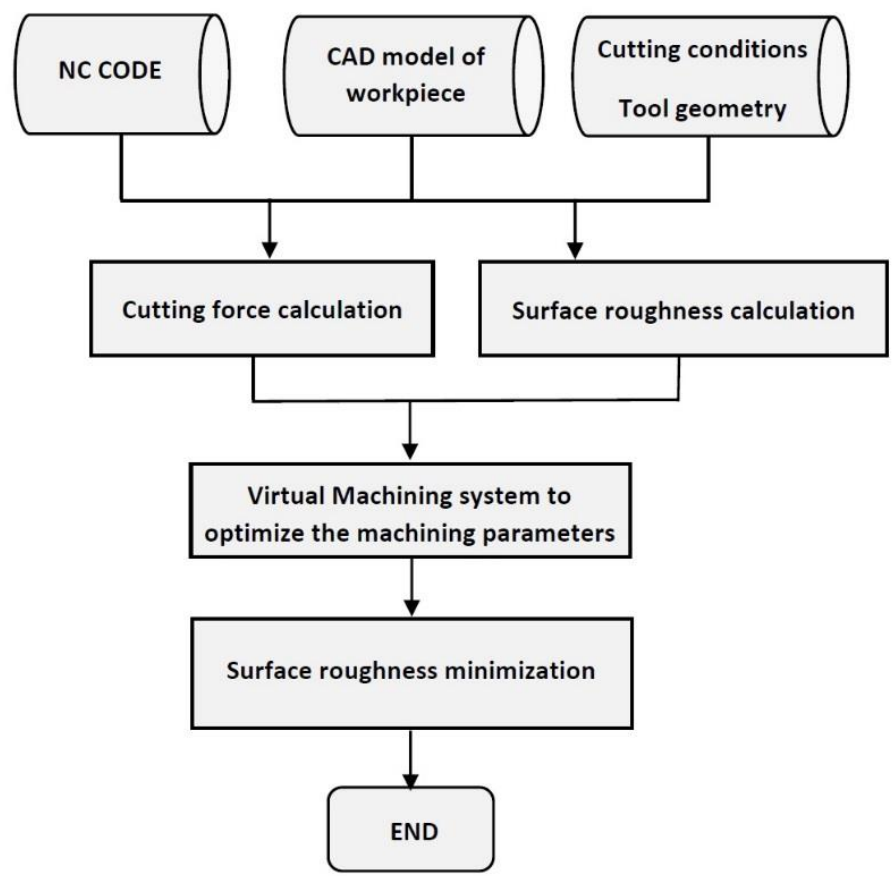


Fig. 6. Flowchart of the virtual machining system used in the calculation of cutting force to minimize the surface roughness of the machined parts.

The algorithm of the virtual machining system is presented in Appendix B.

\section{7- Validation}

To validate the presented virtual machining system, the impeller was machined using the A 5-axis CNC milling machine tool Kondia HM 1060. The turbine blade material was Stainless Steel - Grade 420. The dimensions of the turbine blade in the millimeter unit are shown in Figure 7.

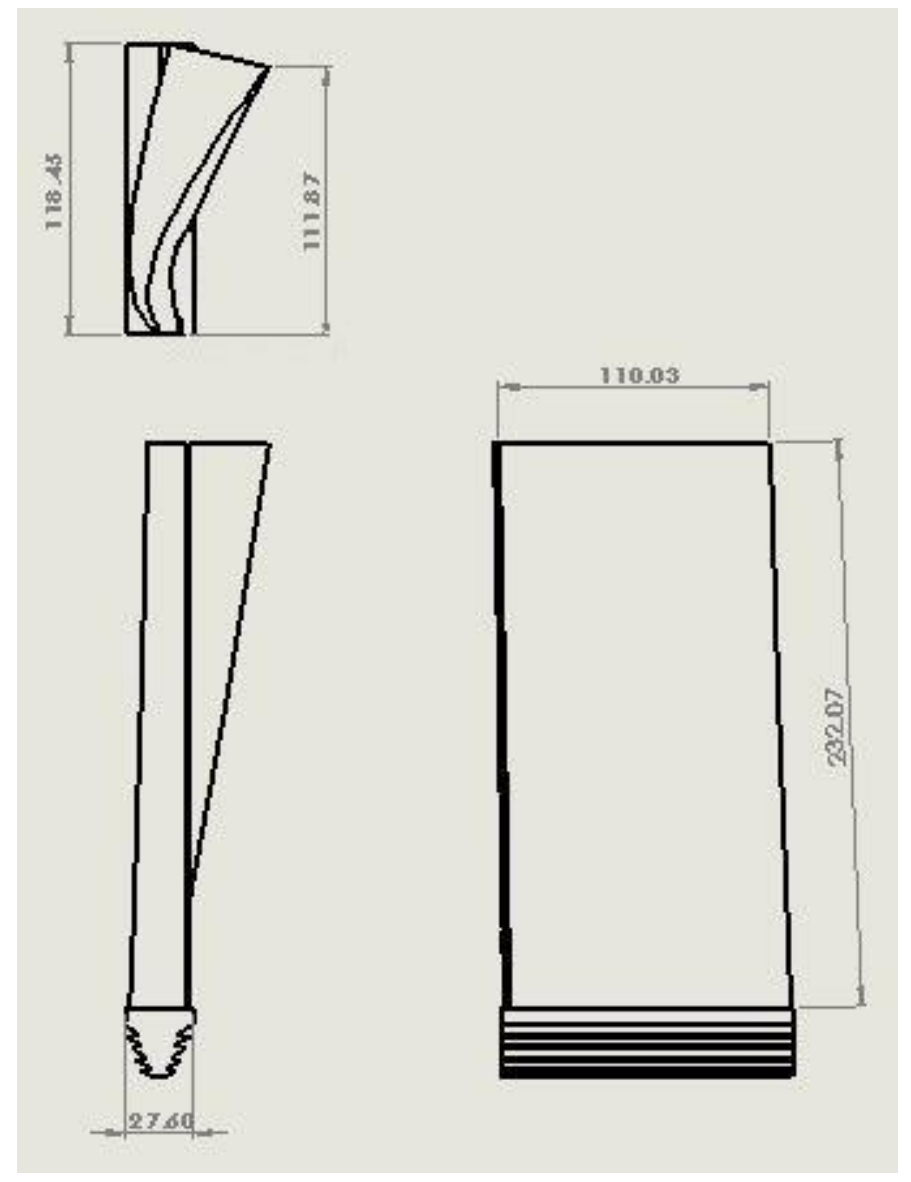

Fig. 7. Dimensions of the turbine blade.

To produce the turbine blade using machining operation, the 5-axis Kondia HM 1060 CNC machine tool was employed. The cutting tool used in the experiment is a carbide end mill with diameter of $20 \mathrm{~mm}$, helix angel of $30^{\circ}$, flute number of 4 , overall length of $90 \mathrm{~mm}$, and cutting edge length of $35 \mathrm{~mm}$. The spindle speed and feed rate, and step over were $250 \mathrm{~m} / \mathrm{min}, 300 \mathrm{~mm} / \mathrm{min}$, and $4 \mathrm{~mm}$, respectively. The machining operation of the turbine blade is depicted in Figure 8. 


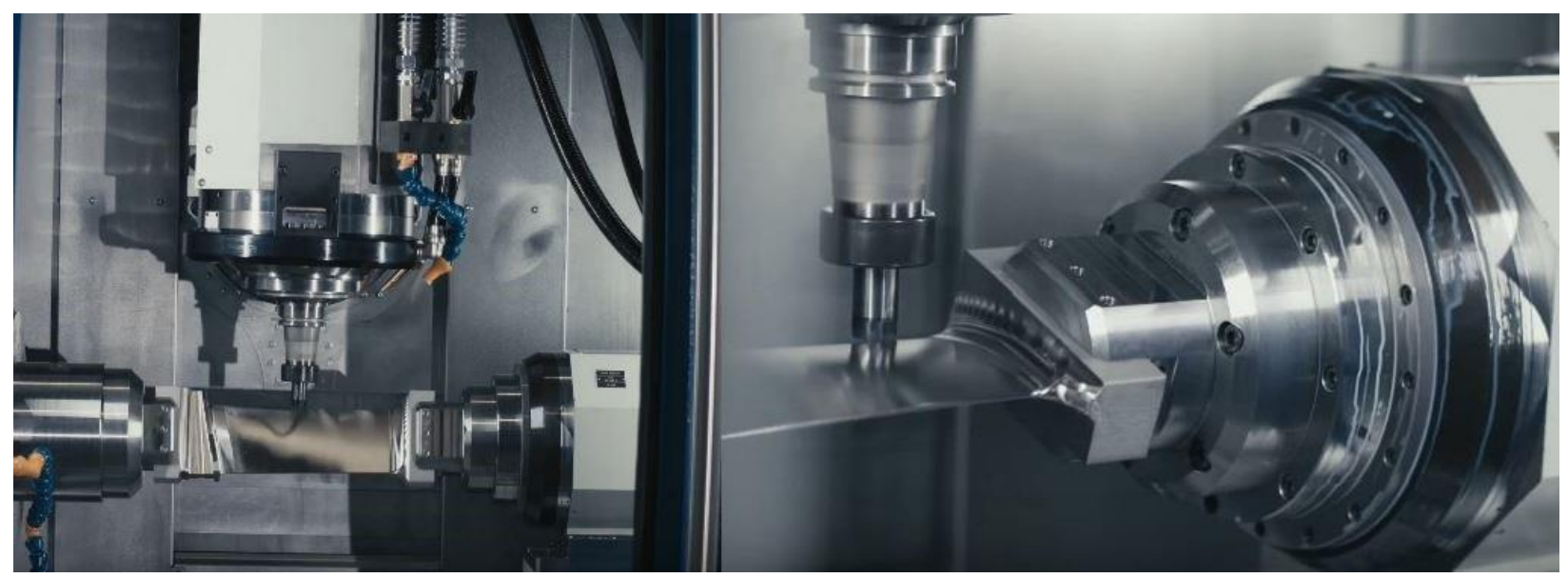

Fig. 8. Machining operations of the turbine blade.

The real machined turbine blade is shown in Figure 9.

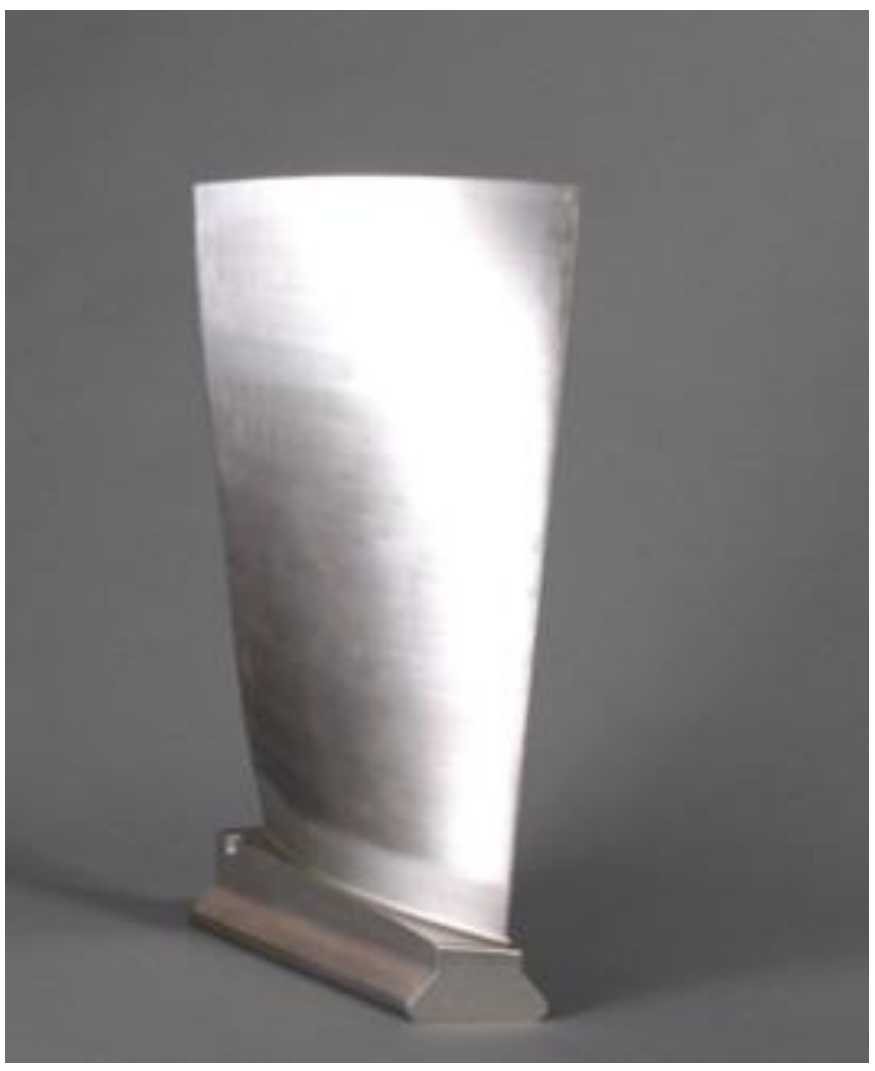

Fig. 9. The real machined turbine blade.

To measure the surface roughness of the machined turbine blade, the CMM machine was applied. The Renishaw SFP2 probe [41] was also used in the surface roughness measuring process of the machined blade. It is a skidded probe with a $2 \mu \mathrm{m}$ radius diamond stylus tip. In the surface roughness measuring process, the skid is held against the surface with a controlled force of approximately $0.2 \mathrm{~N}$ whilst the stylus tip force is $0.005 \mathrm{~N}$. Then, a sensor at the end of the probe can detect and report the skid angles changing in moving to the surface of the test part as the size 
of the surface roughness. The Renishaw SFP2 probe and the measurement method to measure the surface finish of machined parts are shown in Figures 10 and 11.

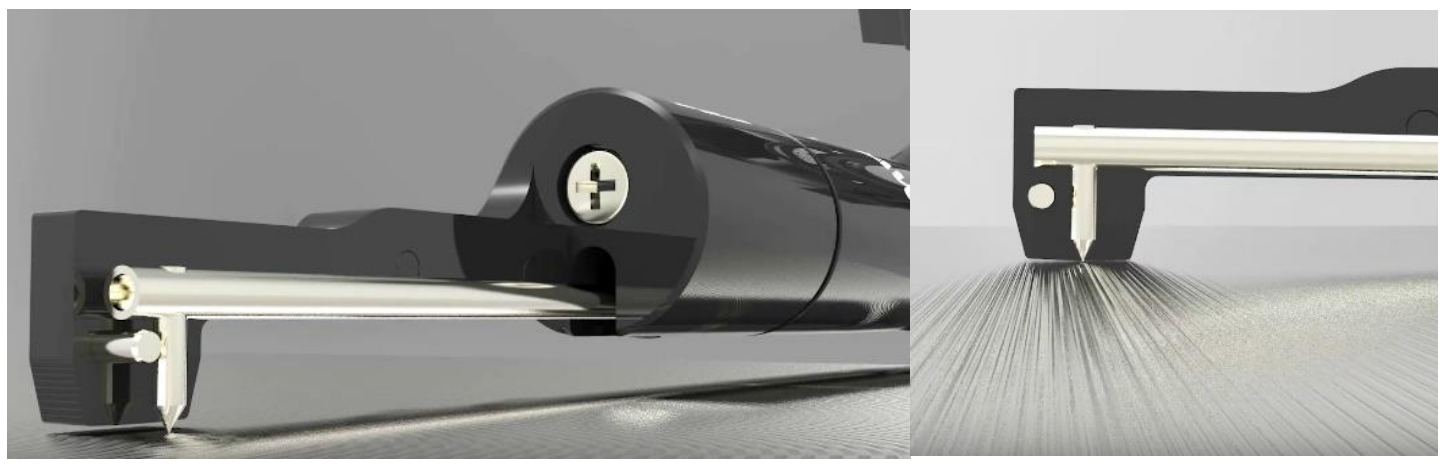

Fig. 10. The Renishaw SFP2 probe to measure the surface roughness of samples.
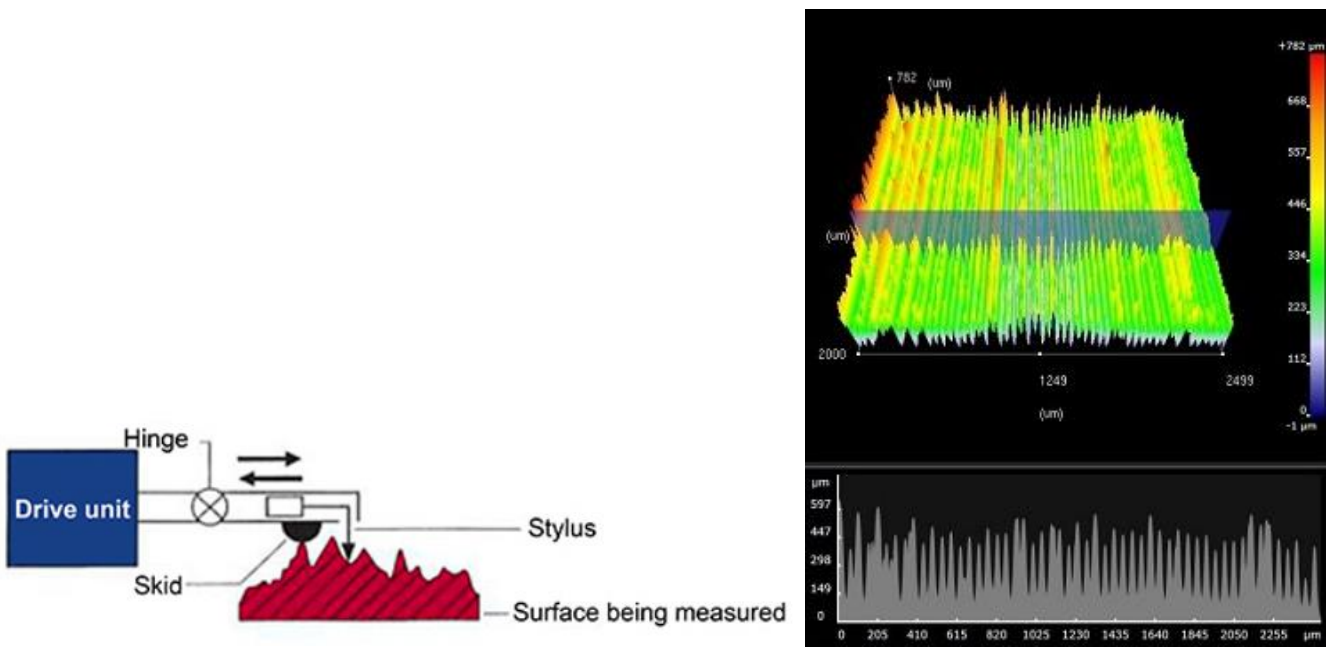

Fig. 11. Measurement method of surface finish using the Renishaw SFP2 probe.

The process of surface roughness measurement of the machined blade using the $\mathrm{CMM}$ is shown in Figure 12 . 


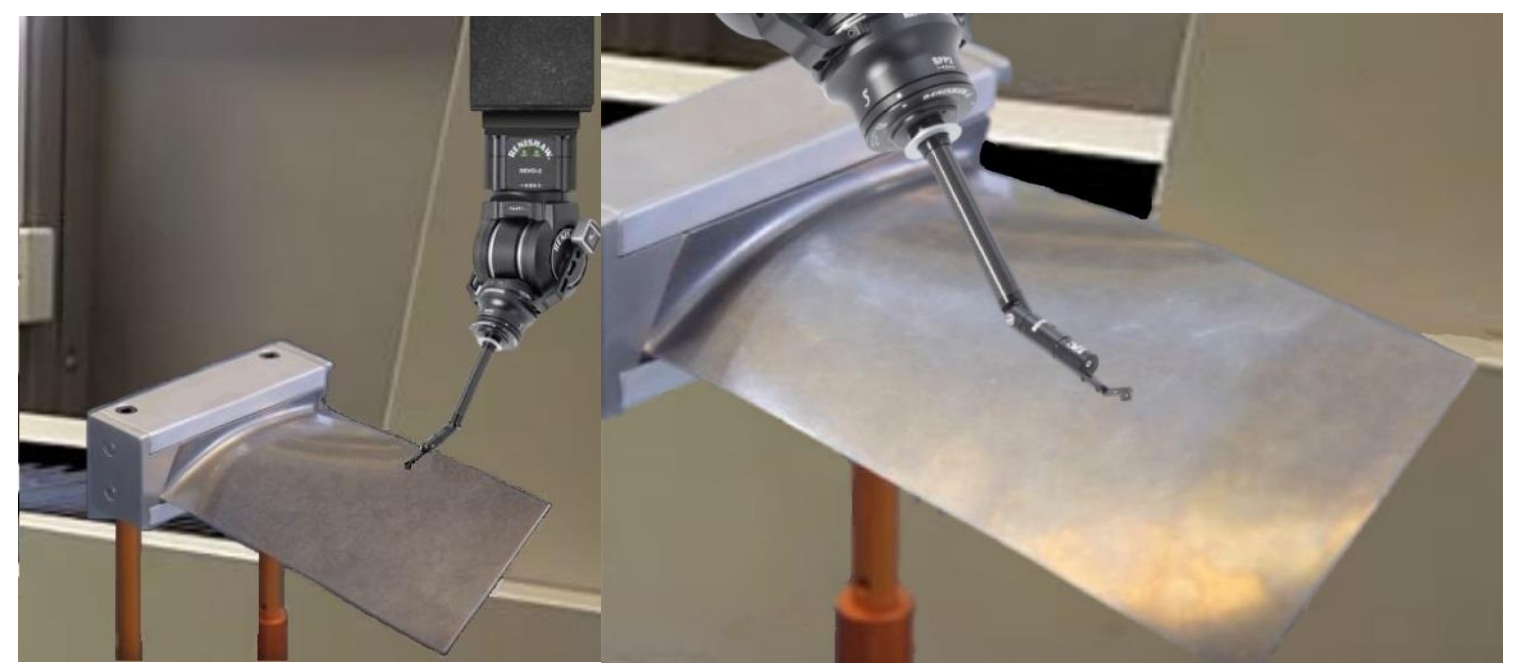

Fig. 12. The process of surface roughness measurement using the $\mathrm{CMM}$ machine.

The cutting force model of 5-axis CNC machine tools in machining operations of thin walled parts presented by Zhang et al. [34] is used in this study to calculate the cutting forces in virtual environments. The average of cutting forces for milling operations of thin walled blades by using 5-axis CNC milling machine tool Kondia HM 1060 are measured by Kistler dynamometer in order to calculate the coefficients of specific cutting force. The spindle rotating speed is $3000 \mathrm{rpm}$ and the feed per tooth and feed rate are $0.5 \mathrm{~mm} 100 \mathrm{~mm} / \mathrm{min}$ respectively. As result, the specific cutting force coefficients are obtained as table 1.

\begin{tabular}{|c|c|c|c|c|c|c|}
\hline $\begin{array}{c}\text { The specific } \\
\text { cutting force } \\
\text { coefficients }\end{array}$ & $K_{r c}\left(\mathrm{~N} / \mathrm{mm}^{2}\right)$ & $K_{r e}(\mathrm{~N} / \mathrm{mm})$ & $K_{t c}\left(\mathrm{~N} / \mathrm{mm}^{2}\right)$ & $K_{t e}(\mathrm{~N} / \mathrm{mm})$ & $K_{a c}\left(\mathrm{~N} / \mathrm{mm}^{2}\right)$ & $K_{a e}(\mathrm{~N} / \mathrm{mm})$ \\
\hline & 215.67 & 12.2 & 480.98 & 11.65 & 148.9 & 0.92 \\
\hline
\end{tabular}

Table 1. The specific cutting force coefficients.

The measured and predicted surface roughness of the machined turbine blade are presented in Figure 11 . A $92.5 \%$ compatibility was obtained compared to the experimental results and predicted surface roughness. Optimized machining parameters were calculated using the developed optimization techniques based on the genetic algorithm. In the optimization process, the population size of 36 was selected with the iterated for 321 generations. Moreover, the crossover and mutation probabilities were set at 0.75 and 0.001 , respectively. The feed rate and the spindle speed were obtained as $255 \mathrm{~mm} / \mathrm{min}$ and $310 \mathrm{~m} / \mathrm{min}$, respectively. Measured and predicted surface roughness of the machined turbine blade are shown in Figure 13. 


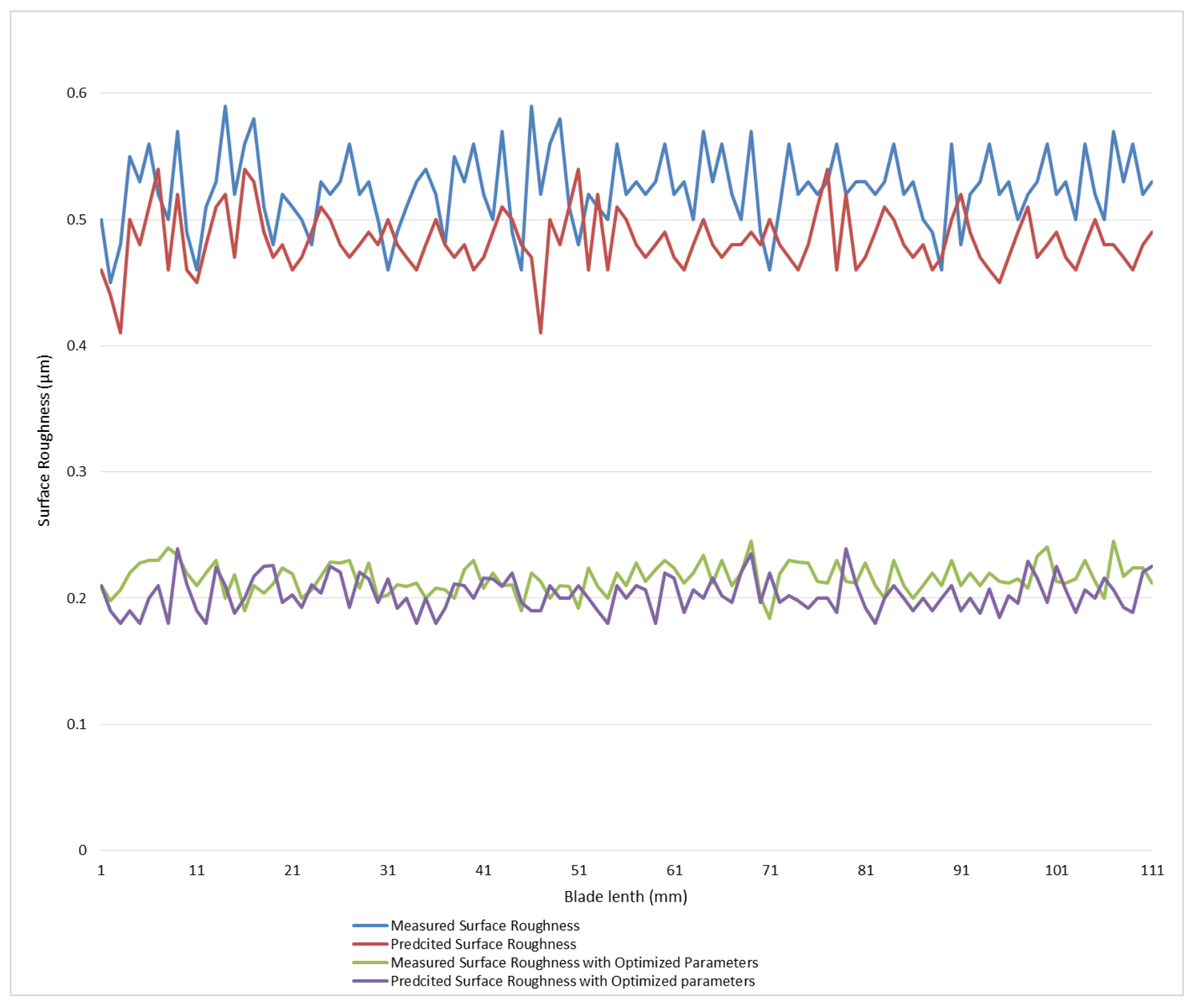

Fig. 13. Measured and predicted surface roughness of the machined turbine blade.

\section{8- Conclusion}

In this research, a virtual machining system was developed to predict and minimize the surface roughness in 5-Axis milling operations of turbine blades. To minimize the surface roughness of machined blades, machining parameters were optimized using the genetic algorithm. To validate the developed virtual machining system in minimization of the surface roughness, a real turbine blade was machined by a 5-Axis CNC machine tool. The surface roughness of the machined blades was measured by the CMM machine. The obtained results from the measured data and predicted data from the virtual machining system were compared in the diagrams and a compatibility of $91.5 \%$ was attained. The optimized machining parameters were used to decrease the surface roughness in machining operations of turbine blades. Results showed a $41.29 \%$ reduction in the measured surface roughness and a $42.09 \%$ decline in the predicted surface roughness by using the optimized machining parameters. The obtained results proved the efficiency of the developed methodology in enhancing the surface quality of the machined turbine blades by applying the developed optimization methods in virtual machining systems. The quality as well as efficiency of the turbine blade manufacturing process can be increased which can raise the energy production productivity in the power plants. Moreover, the developed system can remove the demand of polishing operations for machined blades 
in terms of surface quality enhancement process. As a result, cost of accurate production can be decreased and reliability of produced blades can be increased by applying the developed virtual machining system in the study to process of turbine blade machining operations. Also, the presented system in the study can be extended to other applications of turbine blade machining operations in terms of accuracy and quality enhancement of part manufacturing. Deflection errors of turbine blades in the machining operations can be analyzed and compensated to increase the precision of part machining operations which is the topic of our future research.

\section{Ethical Approval}

The research work is completely compliance with ethical standards.

\section{Consent to Participate}

The authors are agree to participate in the scientific research works related to the paper topic.

\section{Consent to Publish}

The authors are agree to publish the research work.

\section{Authors Contributions}

All authors of the paper had contribution in the research, experiments and writhing section of the paper.

\section{Funding}

The authors would also like to thank Prince Sultan University for support through the Structures and Materials Research Laboratory fund.

\section{Competing Interests}

There is no competing interests for the research work.

\section{Availability of data and materials}

The data and materials are available for the authors in the research work.

\section{References}

1. Bai T, Liu J, Zhang W, Zou Z (2014) Effect of surface roughness on the aerodynamic performance of turbine blade cascade. Propulsion and Power Research 3 (2):82-89

2. Al-Khazraji ANI, Al-Shabbani RMA (2017) EFFECT OF POLISHING ON THE FATIGUE RESISTANCE AND RESIDUAL STRESSES FOR THE SHOT PEENED OF 7075-T6 ALUMINUM ALLOY. Al-Qadisiyah Journal for Engineering Sciences 10 (4):420-430

3. Bons JP (2010) A review of surface roughness effects in gas turbines. Journal of turbomachinery 132 (2)

4. Kiran CP, Clement S (2013) Surface quality investigation of turbine blade steels for turning process. Measurement 46 (6):1875-1895

5. Xun L, Chunming G, Peng Z (2018) Influences of milling and grinding on machined surface roughness and fatigue behavior of GH4169 superalloy workpieces. Chinese Journal of Aeronautics 31 (6):1399-1405 
6. Khorasani A, Yazdi MRS (2017) Development of a dynamic surface roughness monitoring system based on artificial neural networks (ANN) in milling operation. The International Journal of Advanced Manufacturing Technology 93 (1-4):141-151

7. Huang PB (2016) An intelligent neural-fuzzy model for an in-process surface roughness monitoring system in end milling operations. Journal of Intelligent Manufacturing 27 (3):689-700

8. Ribeiro J, Lopes H, Queijo L, Figueiredo D (2017) Optimization of cutting parameters to minimize the surface roughness in the end milling process using the Taguchi method. Periodica Polytechnica Mechanical Engineering 61 (1):30-35

9. Ribeiro JE, César MB, Lopes H (2017) Optimization of machining parameters to improve the surface quality. Procedia Structural Integrity 5:355-362

10. Quintana G, Ciurana JD, Ribatallada J (2010) Surface roughness generation and material removal rate in ball end milling operations. Materials and Manufacturing Processes 25 (6):386-398

11. Dabade UA, Sonawane HA, Joshi SS (2010) Cutting forces and surface roughness in machining Al/SiCp composites of varying composition. Machining Science and Technology 14 (2):258-279

12. Chen H, Dai Y, Zheng Z, Gao H, Li X (2011) Effect of crystallographic orientation on cutting forces and surface finish in ductile cutting of KDP crystals. Machining science and technology 15 (2):231-242

13. Tosun N, Cogun C, Inan A (2003) The effect of cutting parameters on workpiece surface roughness in wire EDM. Machining science and technology 7 (2):209-219

14. Gao N, Zhang Y (2019) A low frequency underwater metastructure composed by helix metal and viscoelastic damping rubber. Journal of Vibration and Control 25 (3):538-548

15. Wu T, Cao J, Xiong L, Zhang H (2019) New Stabilization Results for Semi-Markov Chaotic Systems with Fuzzy Sampled-Data Control. Complexity 2019

16. Wu C, Wang X, Chen M, Kim MJ (2019) Differential received signal strength based RFID positioning for construction equipment tracking. Advanced Engineering Informatics 42:100960

17. Huang Z, Zheng H, Guo L, Mo D (2020) Influence of the position of artificial boundary on computation accuracy of conjugated infinite element for a finite length cylindrical shell. Acoustics Australia 48 (2):287-294

18. Zhang C, Wang H (2020) Swing vibration control of suspended structures using the Active Rotary Inertia Driver system: Theoretical modeling and experimental verification. Structural Control and Health Monitoring 27 (6):e2543

19. Qiu T, Shi X, Wang J, Li Y, Qu S, Cheng Q, Cui T, Sui S (2019) Deep learning: A rapid and efficient route to automatic metasurface design. Advanced Science 6 (12):1900128

20. Rafai N, Islam M (2009) An investigation into dimensional accuracy and surface finish achievable in dry turning. Machining science and technology 13 (4):571-589

21. Jesuthanam C, Kumanan S, Asokan P (2007) Surface roughness prediction using hybrid neural networks. Machining science and technology 11 (2):271-286

22. Tangjitsitcharoen S, Thesniyom P, Ratanakuakangwan S (2017) Prediction of surface roughness in ball-end milling process by utilizing dynamic cutting force ratio. Journal of Intelligent Manufacturing 28 (1):13-21

23. Debnath S, Reddy MM, Yi QS (2016) Influence of cutting fluid conditions and cutting parameters on surface roughness and tool wear in turning process using Taguchi method. Measurement 78:111-119

24. Zahoor S, Mufti NA, Saleem MQ, Mughal MP, Qureshi MAM (2017) Effect of machine tool's spindle forced vibrations on surface roughness, dimensional accuracy, and tool wear in vertical milling of AISI P20. The International Journal of Advanced Manufacturing Technology 89 (9-12):3671-3679

25. Karabulut Ş, Karakoç $H$ (2017) Investigation of surface roughness in the milling of Al7075 and opencell SiC foam composite and optimization of machining parameters. Neural Computing and Applications $28(2): 313-327$ 
26. Nurhaniza M, Ariffin M, Mustapha F, Baharudin B (2016) Analyzing the effect of machining parameters setting to the surface roughness during end milling of CFRP-Aluminium composite laminates. International Journal of Manufacturing Engineering 2016

27. Kant G, Sangwan KS (2014) Prediction and optimization of machining parameters for minimizing power consumption and surface roughness in machining. Journal of cleaner production 83:151-164 28. Imani L, Rahmani Henzaki A, Hamzeloo R, Davoodi B (2020) Modeling and optimizing of cutting force and surface roughness in milling process of Inconel 738 using hybrid ANN and GA. Proceedings of the Institution of Mechanical Engineers, Part B: Journal of Engineering Manufacture 234 (5):920-932 29. Soori M, Arezoo B, Habibi M (2017) Accuracy analysis of tool deflection error modelling in prediction of milled surfaces by a virtual machining system. International Journal of Computer Applications in Technology 55 (4):308-321

30. Soori M, Arezoo B, Habibi M (2014) Virtual machining considering dimensional, geometrical and tool deflection errors in three-axis CNC milling machines. Journal of Manufacturing Systems 33 (4):498-507 31. Soori M, Arezoo B, Habibi M (2013) Dimensional and geometrical errors of three-axis CNC milling machines in a virtual machining system. Computer-Aided Design 45 (11):1306-1313

32. Soori M, Arezoo B, Habibi M (2016) Tool deflection error of three-axis computer numerical control milling machines, monitoring and minimizing by a virtual machining system. Journal of Manufacturing Science and Engineering 138 (8)

33. Altintas $Y$, Merdol $S$ (2007) Virtual high performance milling. CIRP annals 56 (1):81-84

34. Zhang X, Zhang J, Pang B, Zhao W (2016) An accurate prediction method of cutting forces in 5-axis flank milling of sculptured surface. International Journal of Machine Tools and Manufacture 104:26-36 35. Luo S, Dong Z, Jun MB (2017) Chip volume and cutting force calculations in 5-axis CNC machining of free-form surfaces using flat-end mills. The International Journal of Advanced Manufacturing Technology 90 (1-4):1145-1154

36. Reddy NSK, Rao PV (2005) Selection of optimum tool geometry and cutting conditions using a surface roughness prediction model for end milling. The International Journal of Advanced Manufacturing Technology 26 (11-12):1202-1210

37. Palanisamy P, Rajendran I, Shanmugasundaram S (2007) Optimization of machining parameters using genetic algorithm and experimental validation for end-milling operations. The International Journal of Advanced Manufacturing Technology 32 (7-8):644-655

38. Rao V, Rao P (2006) Effect of workpiece curvature on cutting forces and surface error in peripheral milling. Proceedings of the Institution of Mechanical Engineers, Part B: Journal of Engineering Manufacture 220 (9):1399-1407

39. Law KM, Geddam A, Ostafiev V (1999) A process-design approach to error compensation in the end milling of pockets. Journal of Materials Processing Technology 89:238-244

40. Tolouei-Rad M, Bidhendi I (1997) On the optimization of machining parameters for milling operations. International Journal of Machine Tools and Manufacture 37 (1):1-16

41. About the Renishaw. https://www.renishaw.com/cmmsupport/knowledgebase/en/sfp2--22121. 2020

\section{Appendix A}

1 Generate the binary codes from the parameters of machining operation

2 Calculate the fitness function of the optimization process

3 Create the initial population from the produced binary codes

4 Assess the initial population using the fitness functions

5 Implement the crossover to generate new chromosomes in the initial population 
6 Apply mutation

7 Assess the initial population using constrains

8 Check the result regarding the acceptable condition

9 If the result is OK

10 Go to 14

11 Else

13 Go to 4

14 End if

15 Print the optimized parameters of machining operation

16 END

\section{Appendix B}

1- Input

Read G-Codes to obtain (G01, G02, G03, X, Y, Z, R, Feed rate, Depth of cut, and Spindle Speed)

2- Calculation of cutting forces

Enter the specifications and details of the cutting tool as (Flat end, Ball nose end, Ball end, Taper end) and (Lengths, Number of flutes, Diameters)

Obtain the cutting forces along machining paths using the cutting force coefficient (Kts, Krs, Kas, Ktp, Krp, Kap)

Transfer the calculated amount of the cutting forces to the Abaqus software to obtain the residual stress

3- Calculation of surface roughness

Obtain the surface roughness along machining paths

4- Minimizing the residual stress

Calculate the optimized parameters of machining operation using Appendix B

Calculate the surface roughness by using optimized machining parameters for each position of cutting tool along machining paths

5- Output

Generate new G-Codes with optimized machining parameters 
Figures

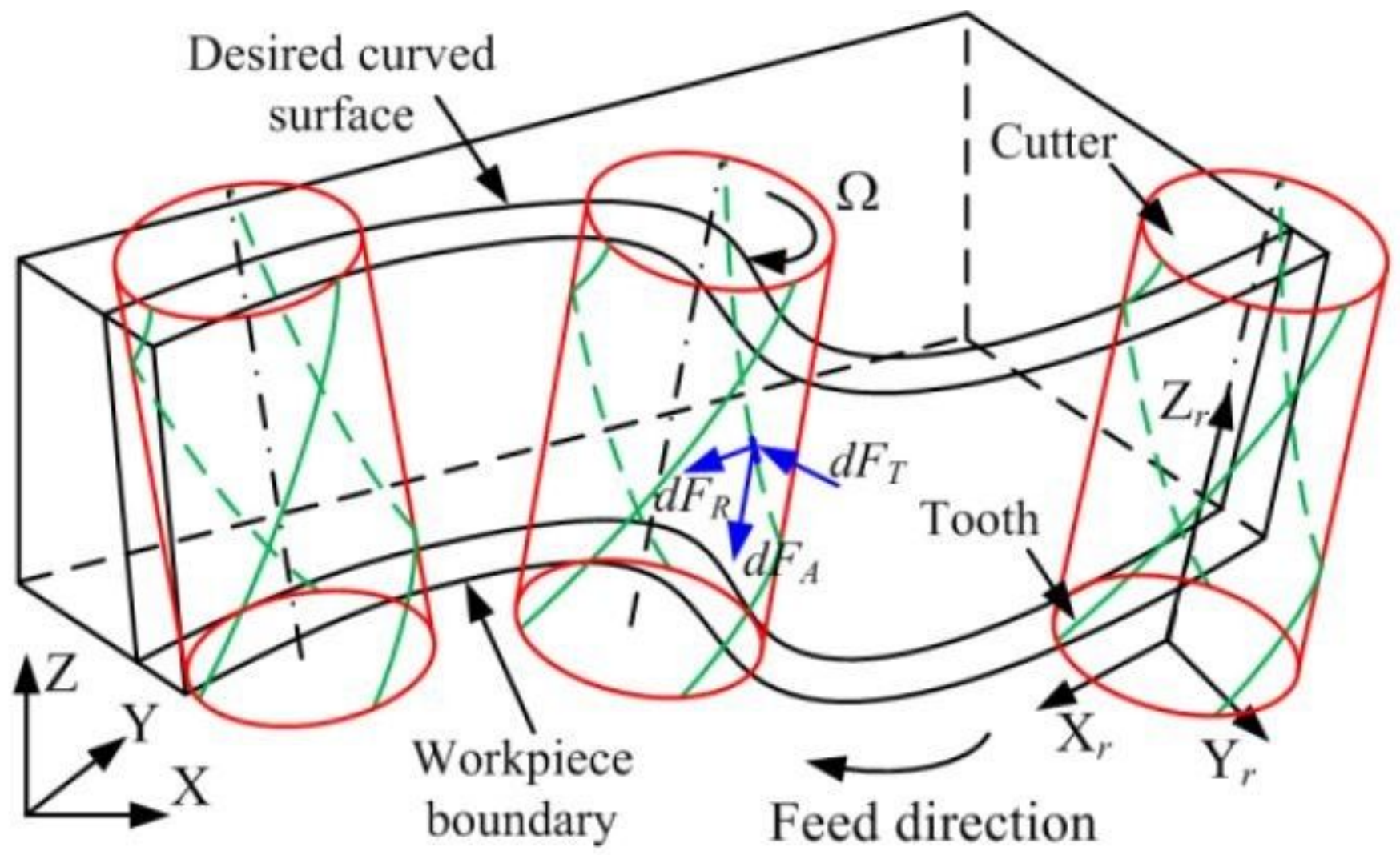

Figure 1

The 5-axis milling operations of free form surfaces [34]. 

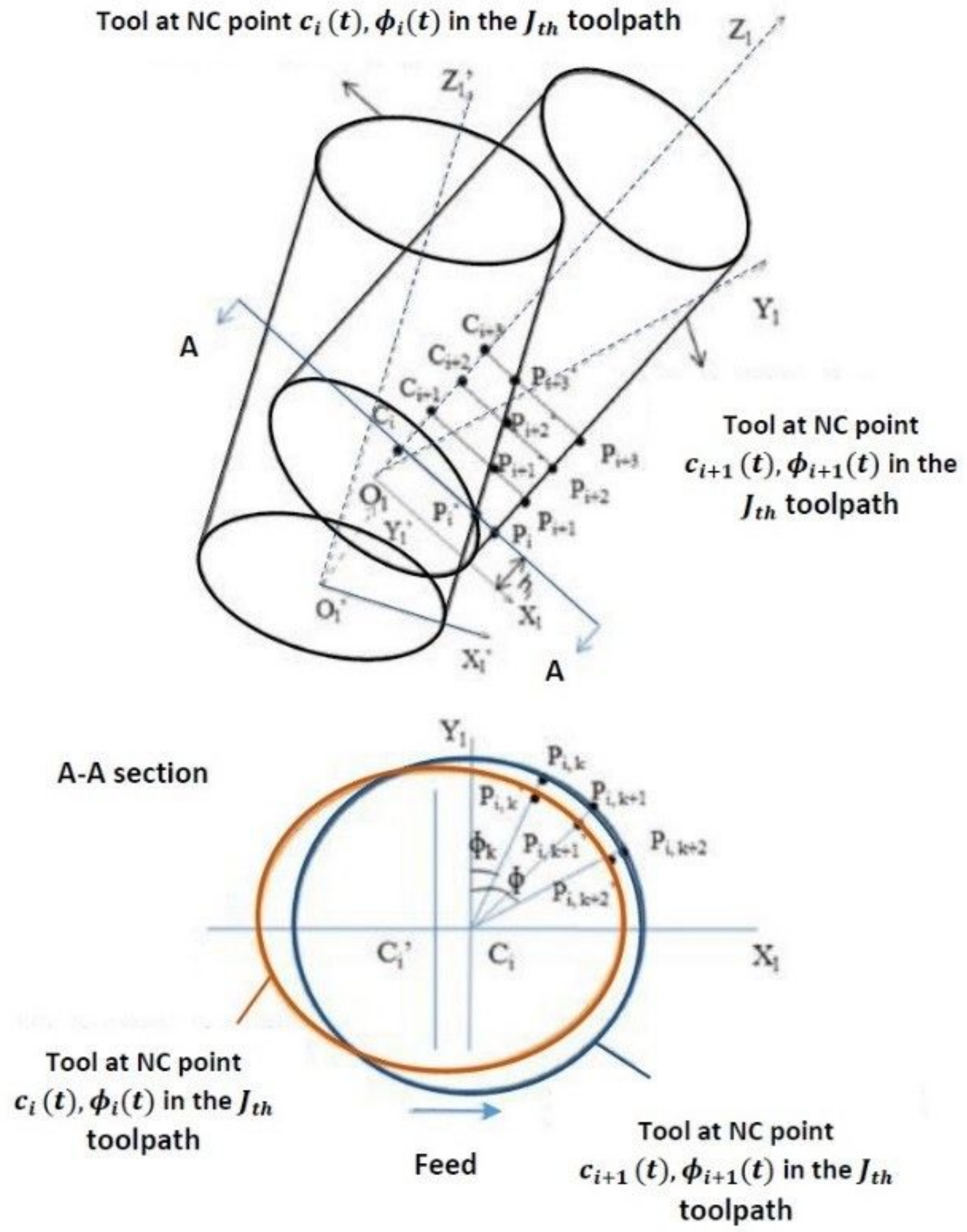

Figure 2

The chip thickness determination along the machining paths free form surfaces using 5 -axis CNC machine tools [35]. 


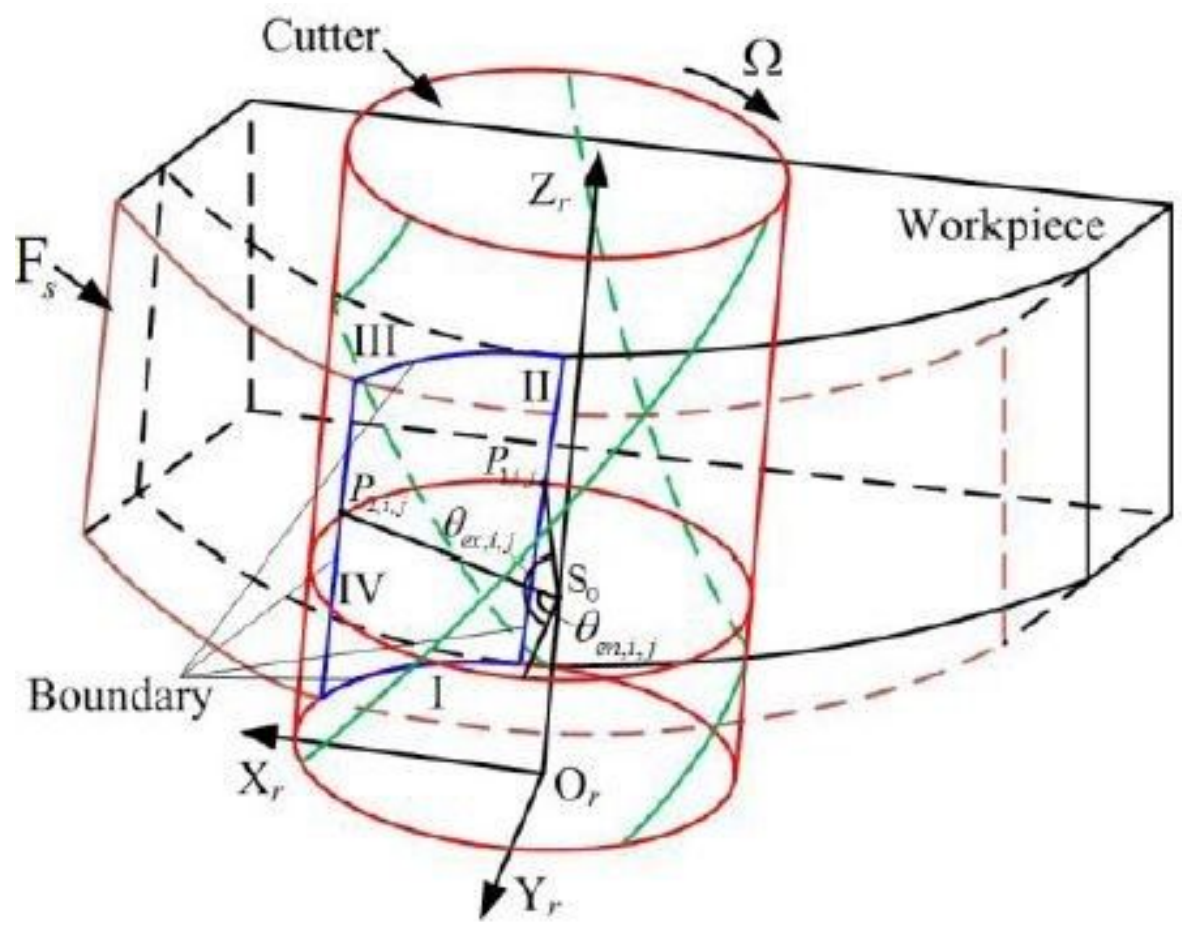

Figure 3

Entry and exit angle model of the cutting tool [34]. 


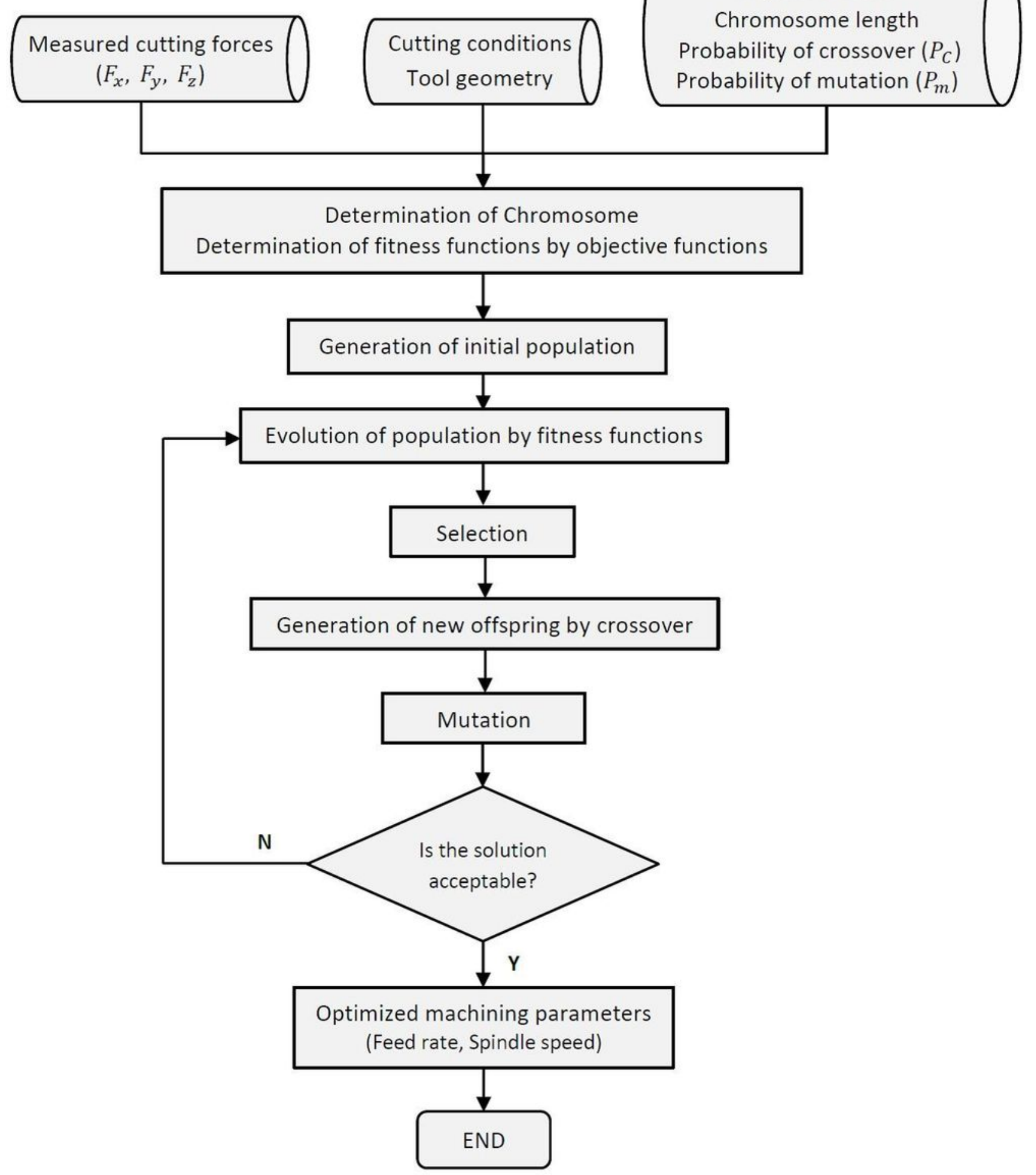

Figure 4

The optimization process of machining parameters. 


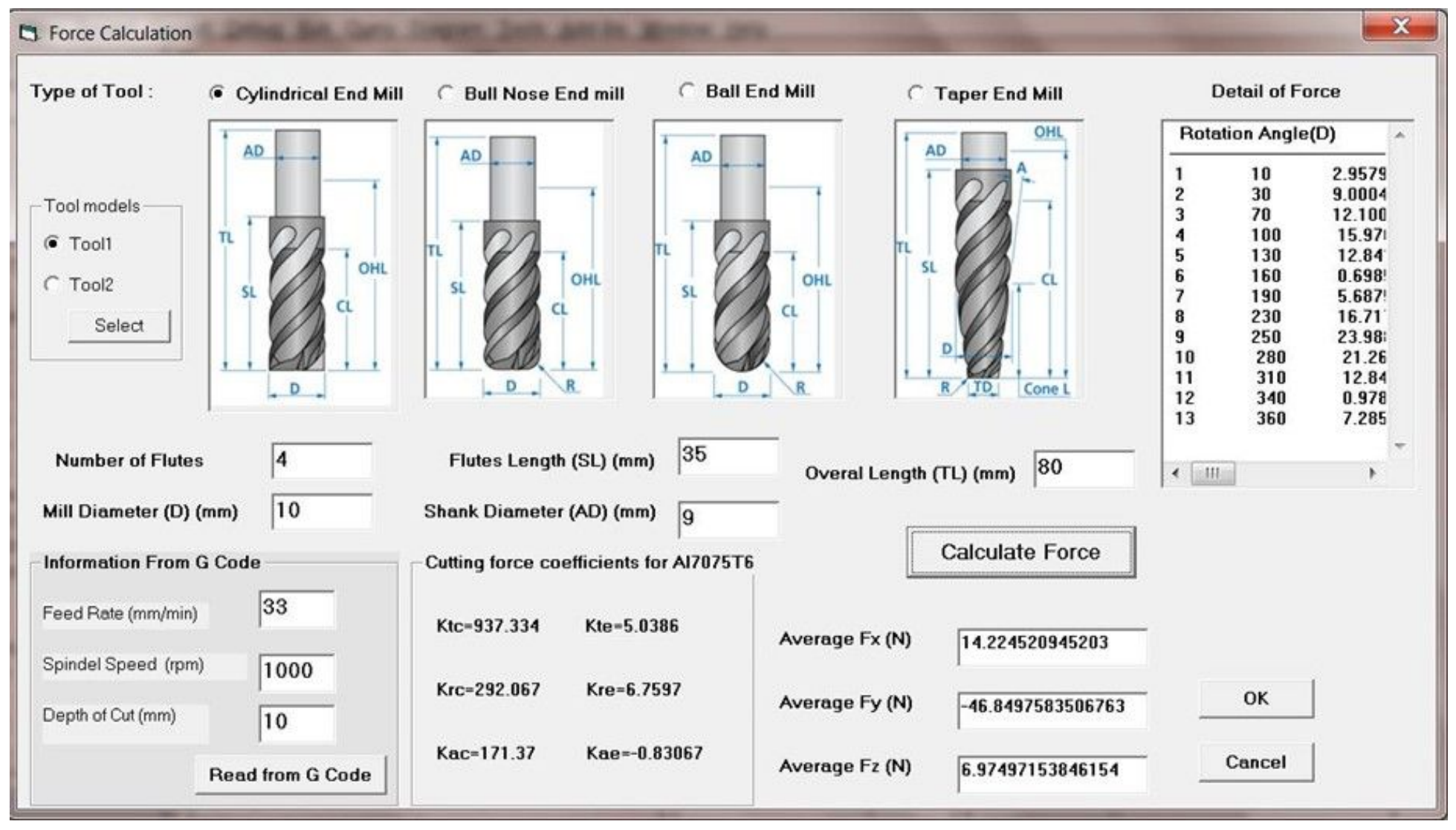

\section{Figure 5}

Dialogue box of cutting force calculator. 


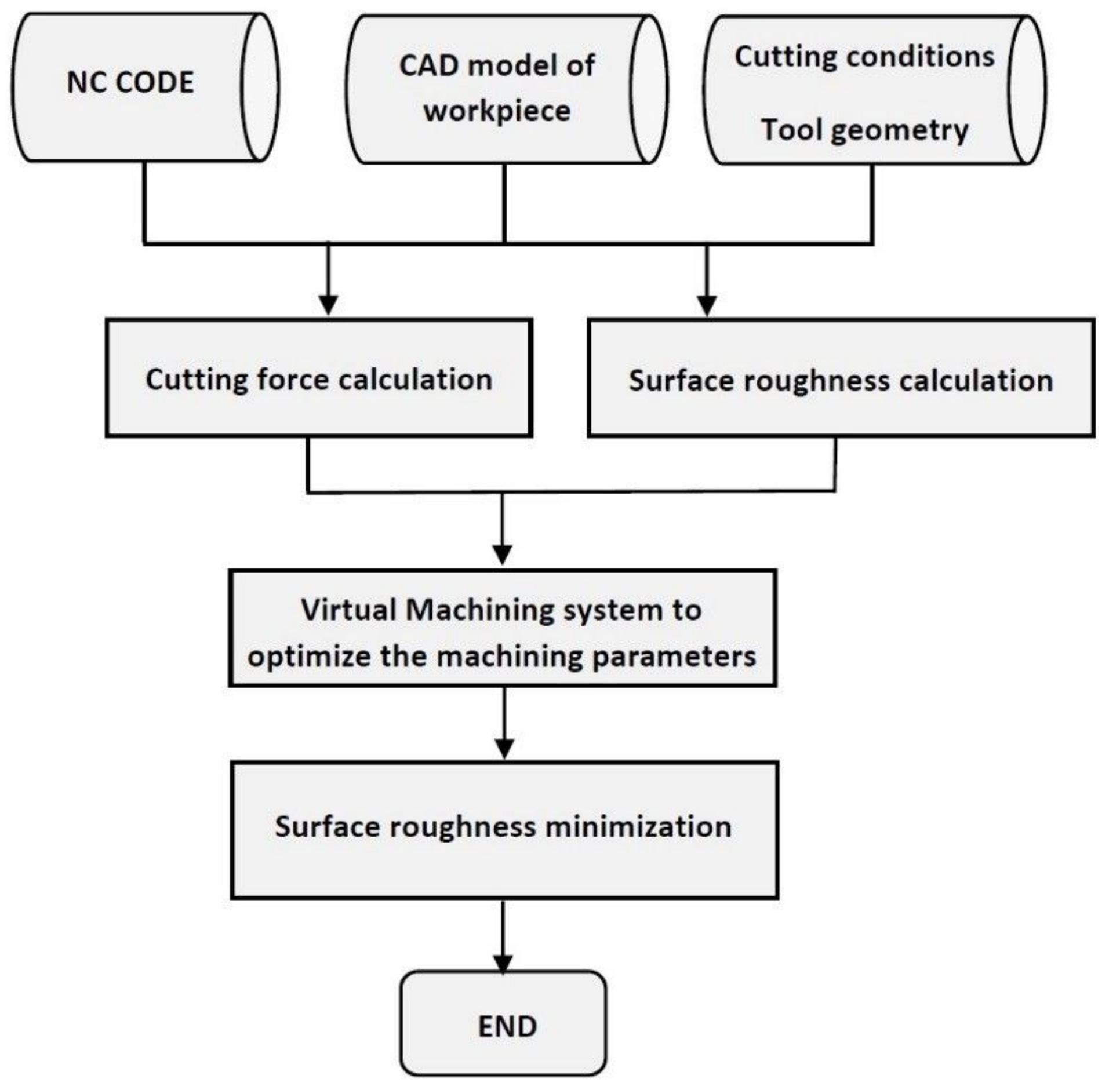

Figure 6

Flowchart of the virtual machining system used in the calculation of cutting force to minimize the surface roughness of the machined parts. 

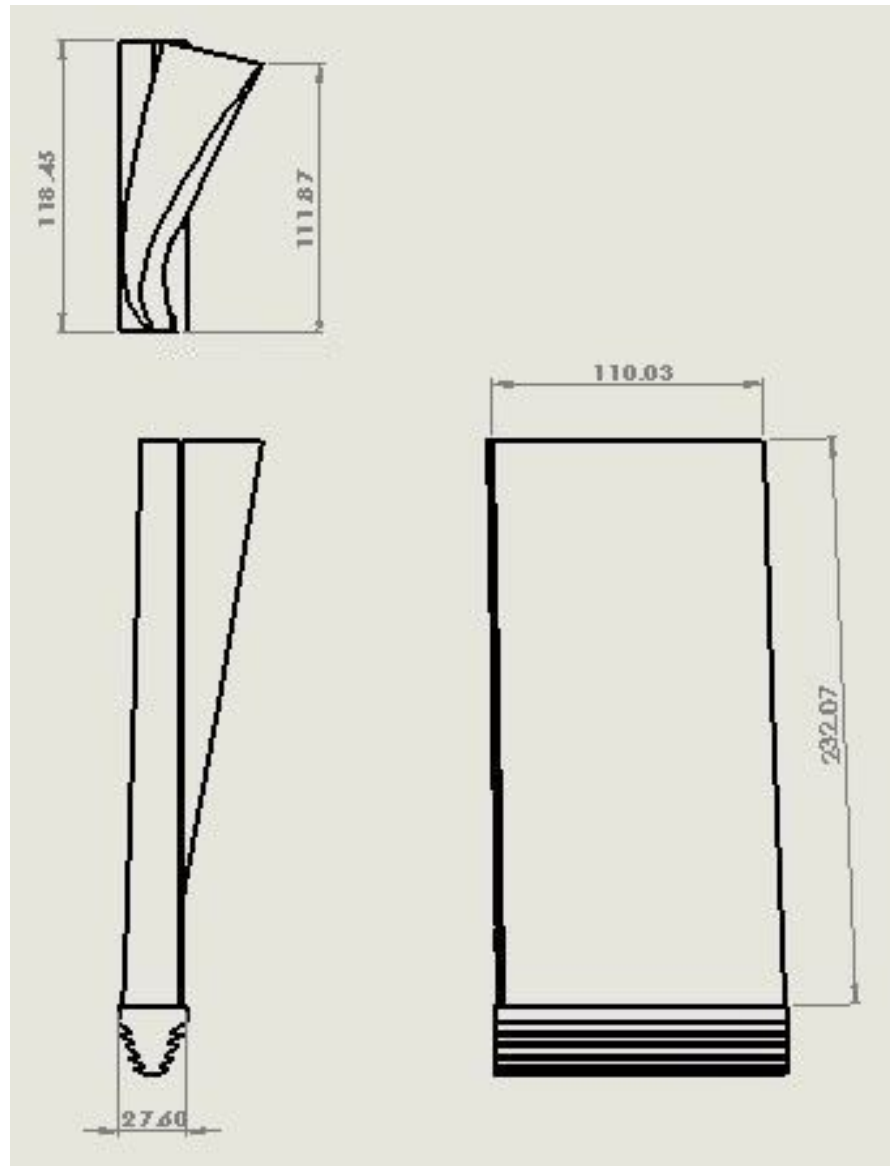

Figure 7

Dimensions of the turbine blade.

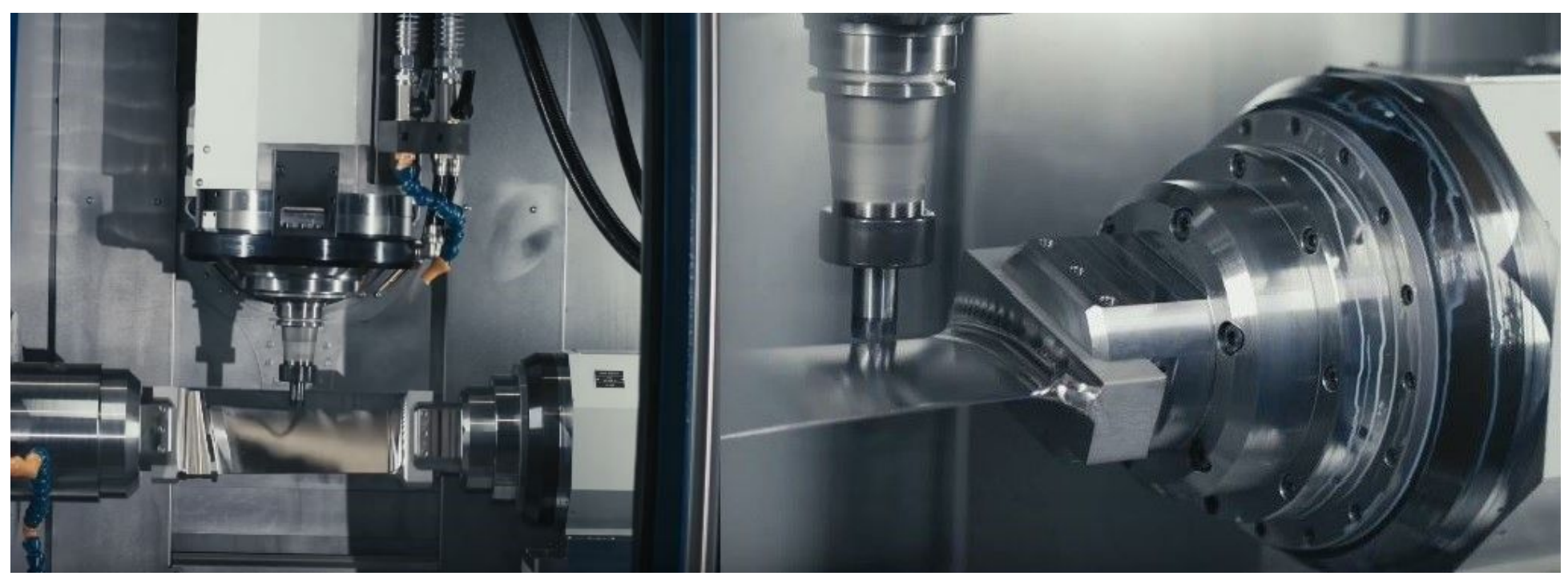

Figure 8

Machining operations of the turbine blade. 


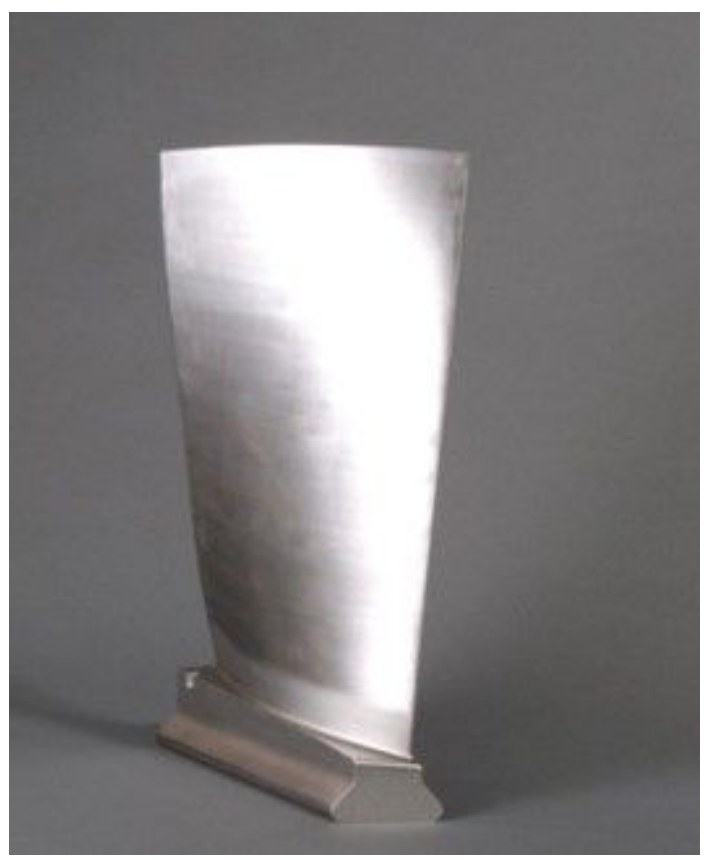

Figure 9

The real machined turbine blade.

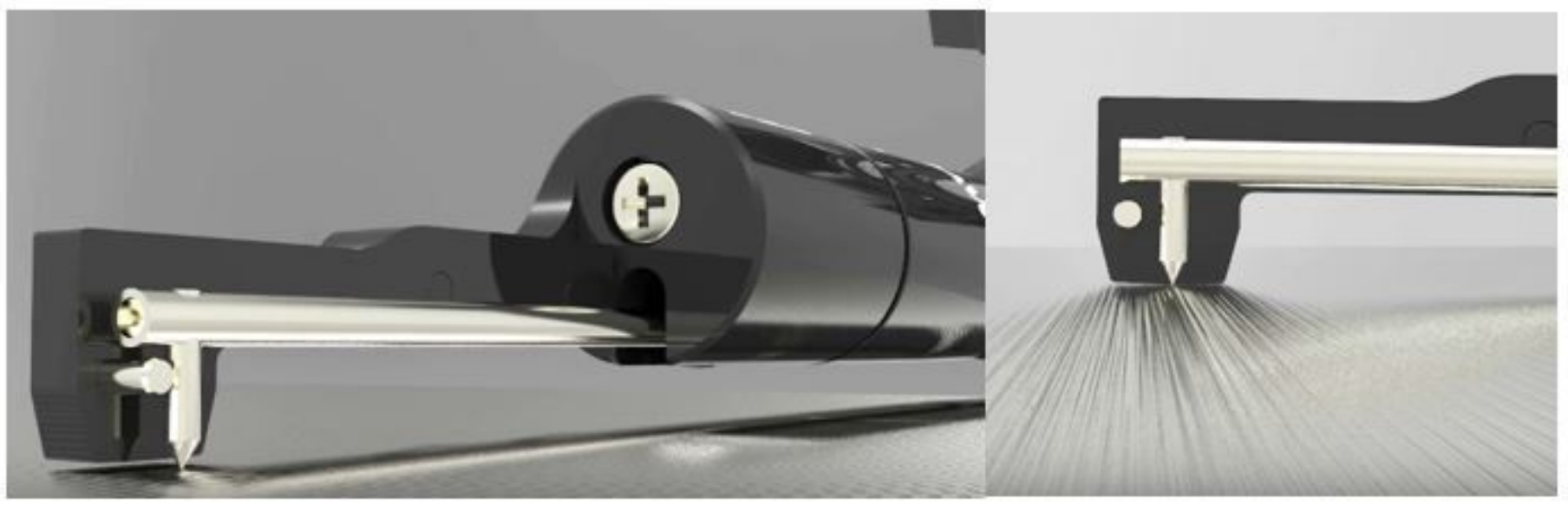

Figure 10

The Renishaw SFP2 probe to measure the surface roughness of samples. 

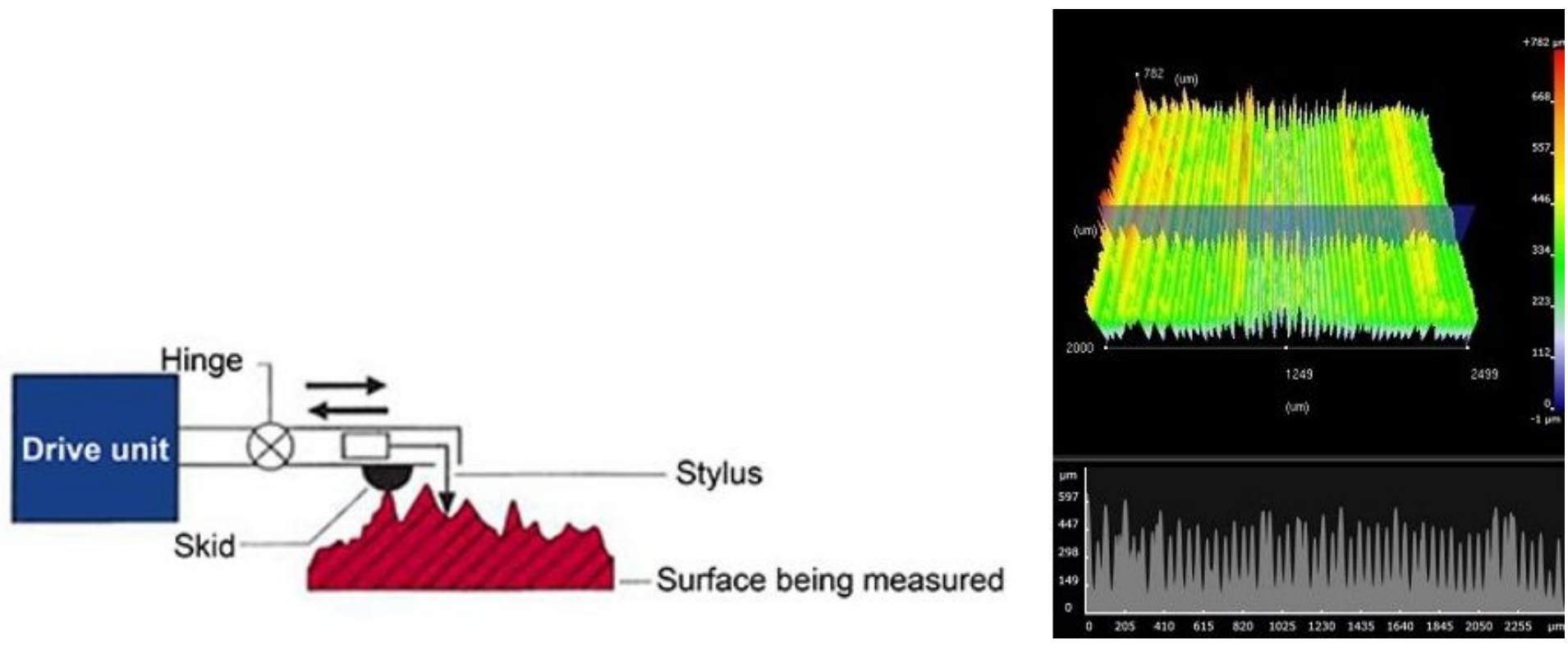

\section{Figure 11}

Measurement method of surface finish using the Renishaw SFP2 probe.

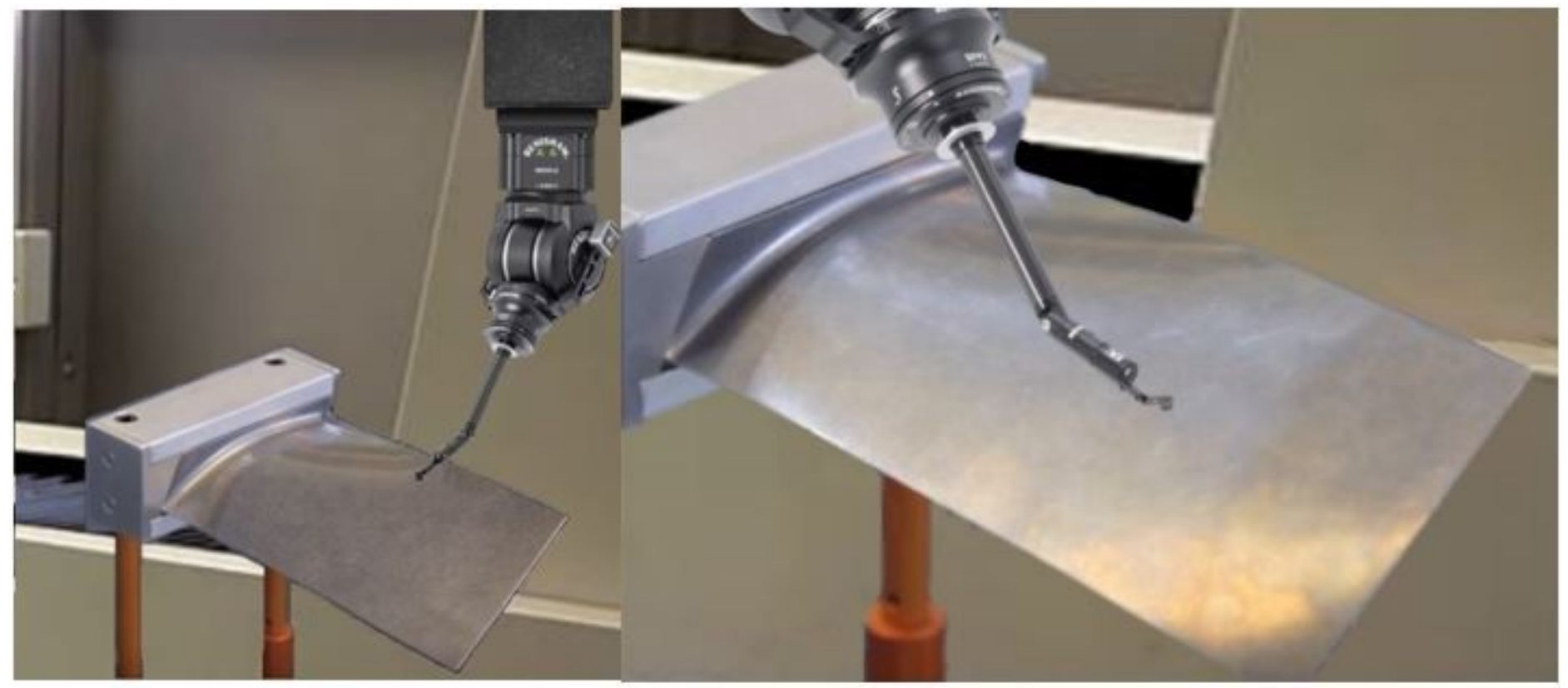

Figure 12

The process of surface roughness measurement using the CMM machine. 


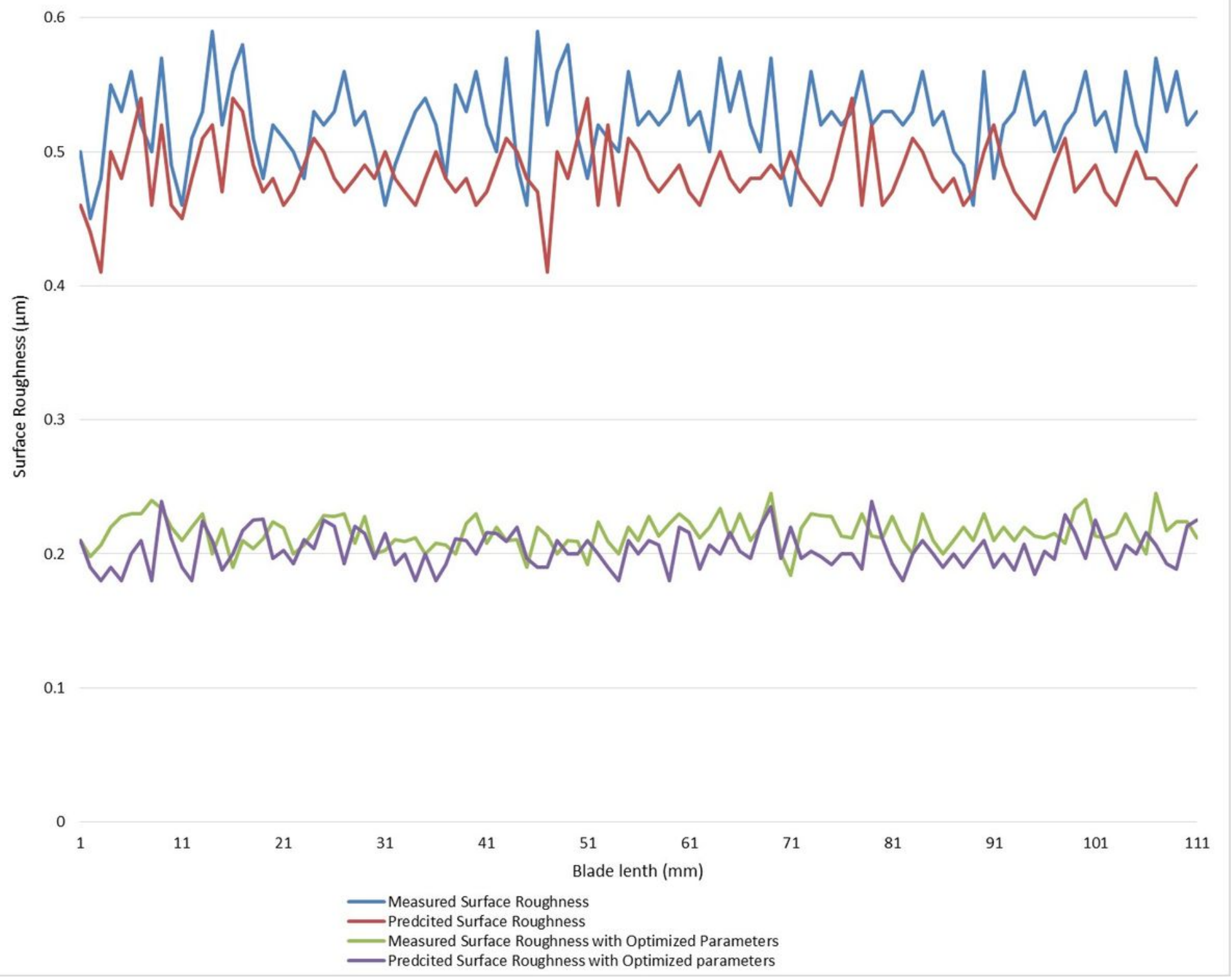

Figure 13

Measured and predicted surface roughness of the machined turbine blade. 